ORNL/TM-13491

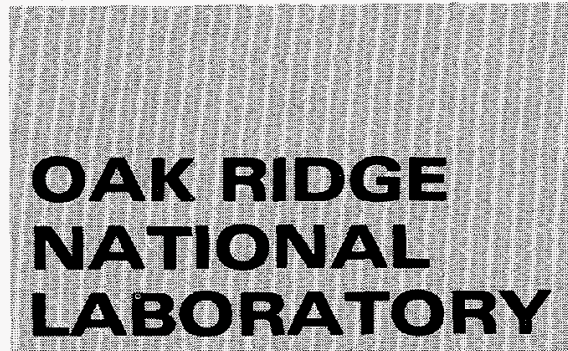

\title{
Materials Used in New Generation Vehicles: Supplies, Shifts, and Supporting Infrastructure
}

\section{Auggust 1997}

Sujit Das

T. Randall Curlee

Susan M. Schexnayder

WLANAGEO RND OPERATED EY LOCKHEEO MARTW EMERCY RESEARCH CORPORATION FOR THE UNTED STATES OEPARTHENT OF ENEROY 
This report has been reproduced directly from the best available copy.

Available to DOE and DOE contractors from the Office of Scientific and Technical Information, P. O. Box 62. Oak Ridge, TN 37831; prices available from (423) 576-8401, FTS 626-8401.

Available to the public from the National Technical Information Service, U.S. Department of Commerce, 5285 Port Royal Road. Springfield. VA 22161.

This report was prepared as an account of work sponsored by an agency of the United States Government. Neither the United States Government nor any agency thereof, nor any of their employees, makes any warranty, express or implied, or assumes any legal liability or responsibility for the accuracy, completeness, or usefulness of any information, apparatus, product, or process disclosed, or represents that its use would not infringe privately owned rights. Reference herein to any specific commercial product, process, or service by trade name. trademark, manufacturer, or otherwise, does not necessarily constitute or imply its endorsement, recommendation, or favoring by the United States Government or any agency thereof. The views and opinions of authors expressed herein do not necessarily state or reflect those of the United States Government of any agency thereof. 


\section{DISCLAIMER}

Portions of this document may be illegible electronic image products. Images are produced from the best available original document. 
ORNL/TM-13491

\title{
Materials Used in New Generation Vehicles: Supplies, Shifts, and Supporting Infrastructure
}

\author{
Sujit Das \\ T. Randall Curlee \\ Susan M. Schexnayder* \\ Energy and Global Change Analysis Section \\ Energy Division \\ Oak Ridge National Laboratory \\ *University of Tennessee \\ Prepared for the \\ Office of Advanced Automotive Technologies \\ Office of Transportation Technologies \\ U.S. Department of Energy
}

August 1997

\author{
Prepared by \\ Oak Ridge National Laboratory \\ Oak Ridge, Tennessee 37831-6205 \\ managed by \\ MARTIN MARIETTA ENERGY RESEARCH CORP. \\ for the \\ U.S. DEPARTMENT OF ENERGY \\ under contract DE-AC 05-96OR22464
}




\section{TABLE OF CONTENTS}

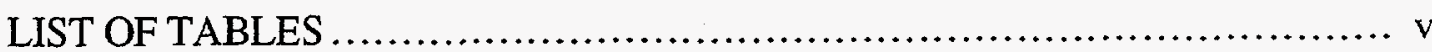

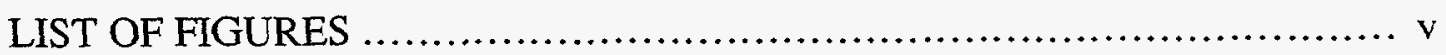

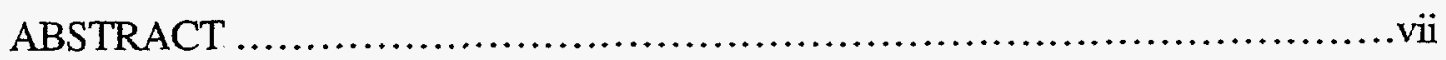

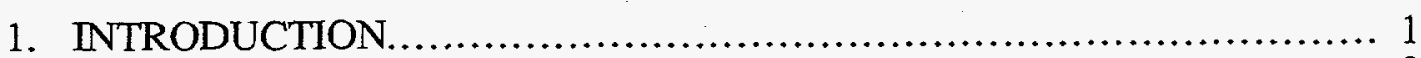

1.1 The Life Cycle of Material Use in Automobiles....................... 2

1.2 Requirements for Material Substitutions............................. 2

1.3 - Organization of Report......................................... 4

1.4 Scenarios .................................................... 4

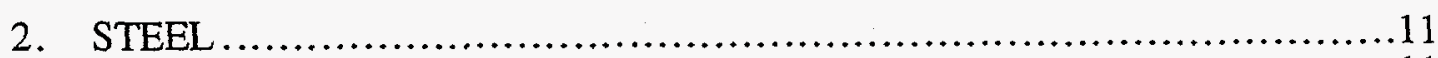

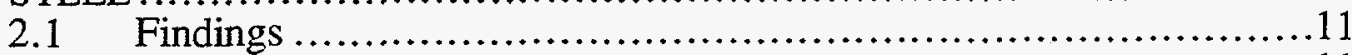

2.2 Baseline and NGV Demand: Material Input .........................11

2.3 Ore Mining/Extraction............................................ 12

2.4 Material Production............................................... 12

2.5 Component Fabrication ........................................ 15

2.6 Vehicle Assembly............................................... 15

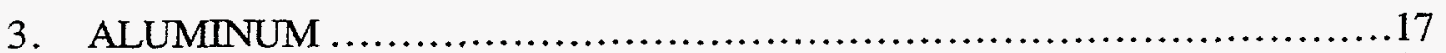

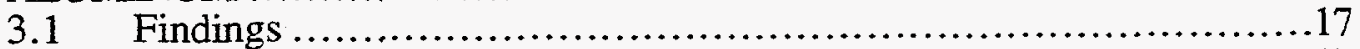

3.2 Baseline and NGV Demand: Material Input .......................... 17

3.3 Mining/Ore Extraction............................................ 21

3.4 Aluminum Smelting and Production .................................22

3.5 Component Fabrication ..............................................24

3.6 Vehicle Assembly................................................ 25

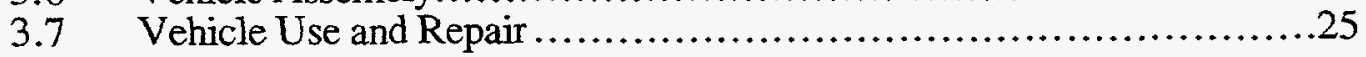

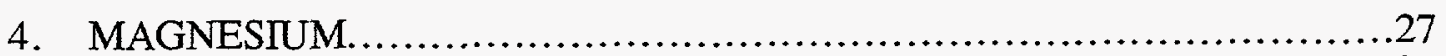

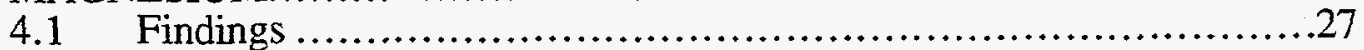

4.2 Baseline and NGV Demand: Material Input............................27

4.3 Extraction/Production ...........................................27

4.4 Component Fabrication ........................................... 30

$4.5 \quad$ Vehicle Assembly..................................................... 30

4.6 Vehicle Use and Repair ........................................ 30

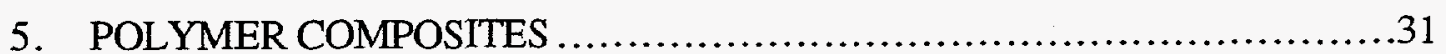

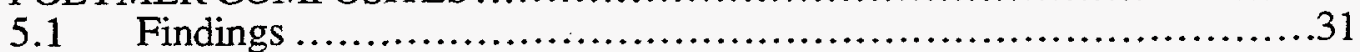

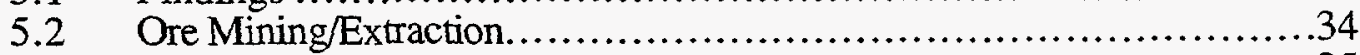

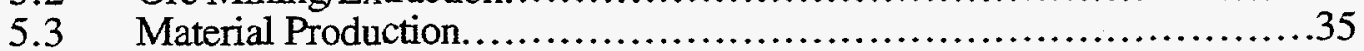

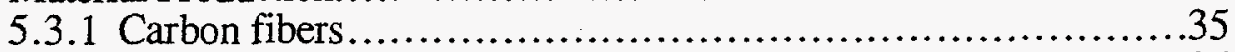

5.3 .2 Glass fibers..................................................

5.3 .3 Resin matrix material ........................................... 37

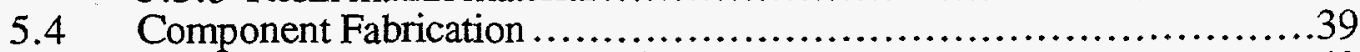

5.5 Vehicle Assembly....................................................40

5.6 Vehicle Use/Repair .............................................41 
TABLE OF CONTENTS (Cont'd)

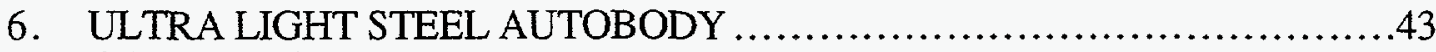

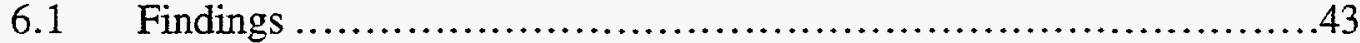

6.2 NGV and Baseline Demand: Material Input .........................43

6.3 Mining/Ore Extraction..............................................43

6.4 Material Production............................................46

6.5 Component Fabrication .........................................47

6.6 Vehicle Assembly..................................................... 48

$6.7 \quad$ Vehicle Use and Repair ............................................ 48

7. NGVs and Automobile Recylcing ..........................................49

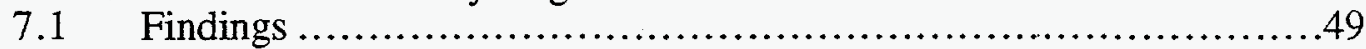

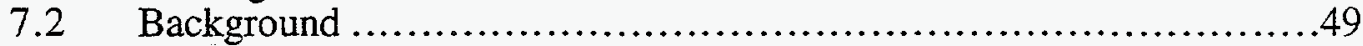

7.3 Economic Viability of the Current Recycle Industry ...................50

$7.4 \quad$ Ultra-Light Steel .................................................. 51

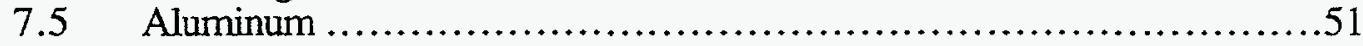

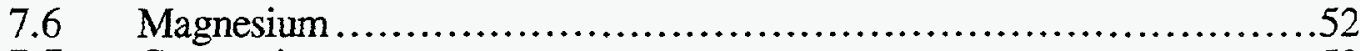

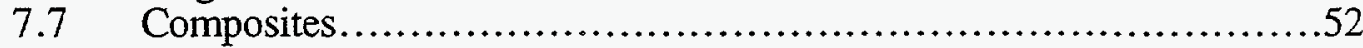

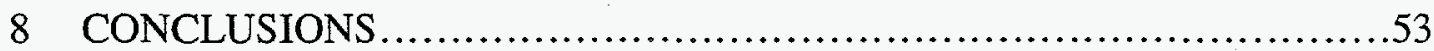

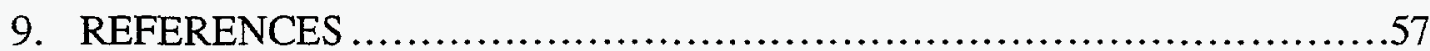




\section{LIST OF TABLES}

Table 1-1. Vehicle mass reduction targets for NGVs .........................4

Table 1-2. Material composition scenarios for PNGV infrastructure: Maximum substitution of individual materials (lbs) .............................6

Table 1-3. Plausible material composition scenarious for NGVs (lbs) ..............7

Table 1-4. Projected vehicle sales and market share $(\&)$ by year .................8

Table 1-5. Lightweight material requirements and reduction in ferrous materials associated with maximum potential material substitution for PNGV, 2007-2030 (figures in ' 000 metric tons) .............................10

Table 2-1. Maximum steel products replaced annually by NGVs by $2030 \ldots \ldots \ldots .13$

Table 3-1. Issues associated with aluminum use in NGVs .....................18

Table 3-2. Increases in aluminum production and associated requirements to meet NGV demand .................................................21

Table 4-1. Issues associated with magnesium use in NGVs ....................28

Table 4-2. Increases in magnesium production and associated requirements to meet NGV demand ...................................................29

Table 5-1. Issues associated with polymer composite use in NGVs ................32

Table 6-1. Issues associated with ULSAB use in NGVs.......................44

\section{LIST OF FIGURES}

Fig. 1-1. Life-cycle stages of automotive materials........................... 3

Fig. 5-1. Glass fiber for composites industry - Global demand vs. capacity.......38

Fig. 8-1. Life-cycle stages in which challenges are expected.......................54 



\section{ABSTRACT}

The Partnership for a New Generation of Vehicles (PNGV) program intends to develop new designs for automobiles that will reduce fuel consumption by two thirds but otherwise have price, comfort, safety, and other measures of performance similar to the typical automobile now on the market. PNGV vehicle designs are expected to substitute lightweight materials, such as aluminum, magnesium, carbon-reinforced polymer composites, glass-reinforced polymer composites, and ultra-light steel, for heavier materials such as steel and iron in automobile components. The target mass of a PNGV vehicle is 1,960 pounds, as compared to the average current vehicle that weighs 3,240 pounds. Other changes could include the use of different ferrous alloys, engineering changes, or incorporation of advanced ceramic components. Widespread adoption of these vehicle designs would affect materials markets and require concurrent development and adoption of supporting technologies to supply the materials and to use and maintain them in automobiles.

This report identifies what would be required to bring about these changes and developments in materials substitution; identifies reasons that might make these substitutions difficult to accomplish within the overall objectives and timetable of the PNGV program; and identifies any issues arising from the substitution that could prompt consideration of policies to deal with them.

The analysis in this paper uses scenarios that assume the production of new generation vehicles will begin in 2007 and that their market share will increase gradually over the following 25 years. The scenarios on which the analysis is based assume a maximum substitution of each potential replacement material considered. This maximum substitution of individual materials (i.e., the amount of replacement material by weight that would be added to the baseline vehicle's composition) is as follows: ULSAB (high strength steel), 298 lbs.; glass-reinforced composites, 653 lbs.; carbonreinforced composites, $379 \mathrm{lbs}$; aluminum, $926 \mathrm{lbs}$; and magnesium, $216 \mathrm{lbs}$. The substitutions (and the steel and iron they replace) are multiplied by the number of new generation vehicles produced on an annual basis out to 2030 to determine the total quantity of material used in new generation vehicles and the quantity of steel that would be displaced.

We identified six stages in the life cycle of materials-mining or extraction of resources; smelting or other processing to produce the material from the resource; producing components from the material; assembling the components into vehicles, using, maintaining, and repairing vehicles; and disposing of the vehicle, including any recycling of materials for automotive or other use-and identified what might be required to supply and use the substitute materials at different life cycle stages. The variables considered are the mineral or material supply, the capital and equipment (including necessary capacity, technical changes, cost, and location), labor and employment, energy, material complements, and environmental emissions and impacts.

The analysis shows that raw materials to produce each of the replacement materials are sufficiently available, and adequate mining or extraction capacity exists for each. However, challenges are possible at the material production stage for three of the four materials. For aluminum and magnesium the difficulties are associated with requirements for significant new production capacity, necessary for aluminum because new production equipment will be needed to produce the material in a cost-effective manner and for magnesium because current production capacity is inadequate. The required capacity investment for magnesium to meet demand in 2030 is $\$ 13.1$ billion. Both materials also would sharply increase energy requirements, and both industries would likely develop mostly-if not entirely-outside the United States. To produce the carbon-based fiber to meet PNGV demand in 2015 , an entire new industry must be developed-a $\$ 4.6$ billion investment. Significant environmental concerns also are associated with carbon fiber production. The glass fiber industry is far more established, but operates at capacity. An estimated investment of $\$ 350$ million would be required to meet demand in 2015. However, if applications require higher-grade glass fibers, the required 
investment would increase more than 5 -fold. Significant growth would also be required in the composites industry for either carbon- or glass-based fibers.

Only composites present a serious challenge at the component fabrication life-cycle stage. The advanced polymer composites likely to be required for NGVs currently account for less than $1 \%$ of the total polymer composite market and represent only 4-5\% of NGV demand in 2015. For each of the other materials, fabrication technologies are well developed but some additional production capacity would be required. Although fabrication methods exists for each material type, the products they produce are not subject to the same performance (strength) and cost requirements that would be required in automotive applications. It could take several product generations to develop this knowhow in an automotive setting. The lack of know-how and the need to develop and refine new production methods are not necessarily barriers to materials substitution, but they are barriers to rapid large-scale materials substitution. If changes in large numbers of well-integrated components that require extensive retooling and are difficult to reverse are needed to reach PNGV goals, automakers may need incentives to undertake a rapid, major design change for a major part of their product lines.

Vehicle assembly presents challenges for ULSAB, which will require new assembly methods, and for aluminum and composites, which would require new joining methods and, thus, new infrastructures to carry them out. At the use-and-repair life cycle stage, aluminum and composites-materials that allow parts consolidation-present challenges. The consolidated parts could make damage repair more expensive by requiring replacement of larger components after an accident, and this could increase the cost of automobile insurance and thus the cost of owning and operating the vehicle.

The three, non-steel replacement materials present potential recycling difficulties. Composites could threaten the economic viability of the current recycling infrastructure because they decrease the amount of recyclable material but increase the waste to be disposed of. Aluminum and magnesium present operational difficulties. Magnesium would increase the risk of fires, potentially decreasing worker safety, increasing liability costs, and requiring new technologies. With aluminum, several technical problems arise, e.g., the incompatibility of different alloys, contamination from paints and adhesives, and potential requirements for hand disassembly. If these problems can be overcome, intensive use of aluminum could favorably affect the financial viability of the industry. 


\section{INTRODUCTION}

The PNGV program intends to develop new designs for automobiles that will reduce fuel consumption by two thirds but otherwise have similar price, comfort, safety, and other measures of performance to the typical automobile now on the market. These vehicle designs are expected to substitute lightweight materials such as aluminum, magnesium, and composites for heavier materials such as steel in automobile components. The designs may also use different ferrous alloys or engineering changes to reduce the weight of steel components. In addition, some designs are expected to incorporate advanced ceramic components to improve engine performance. Widespread adoption of these vehicle designs would cause significant changes in materials markets. Adopting these designs also would require concurrent development and adoption of supporting technologies to supply the materials and to use and maintain them in automobiles.

The purposes of this report are to identify what would be required to bring about these changes and developments in materials substitution; identify any reasons that might make these substitutions difficult to accomplish within the overall objectives and timetable of the PNGV program; and identify any issues arising from the substitution that could prompt consideration of policies to deal with them.

The objectives of the PNGV program-a three-fold improvement in vehicle's fuel economy without affecting cost and performance-impose fairly stringent assumptions on any analysis of the introduction and use of the new generation vehicles. This report provides a partial check on these assumptions. For example, if the adoption of a new material would be likely to increase the cost of vehicle components, then reductions in other costs would be necessary to offset this increase and meet PNGV goals. Because light-weight materials cost more than steel, the PNGV program anticipates that some of the higher cost would be offset by changes in components' design that reduce labor, capital, or other manufacturing costs. Similarly, if there were to be potential bottlenecks in the rapid expansion of supply of a material such as magnesium, then government or other PNGV participants might need to take action to ease the bottlenecks or adjust the program to them. Our purpose here is to project whether offsets or policies might be required to meet PNGV objectives, but not to identify specific actions.

No PNGV design exists from which to do formal cost estimation or market analysis. Hence, the analysis in this paper starts with a set of scenarios developed in collaboration with Argonne National Laboratory that assume that production of new generation vehicles will begin in 2007 and gradually increase their share of the market over the following 25 years. Scenarios meet the program's assumptions about vehicle cost and performance. These scenarios contain estimates of quantities of materials used in new generation vehicles, and estimates of the quantities of steel that would be displaced.

We identified six stages in the life cycle of materials used in automobiles, and a series of variables that are likely to be of interest to auto makers, their parts and materials suppliers, other PNGV stakeholders, and the public. We then reviewed automotive and materials trade literature; examined economic data and projections; and interpreted this material in light of experience and of economic and geographic theory, to identify what might be required to supply and use the substitute materials at different stages of their life cycles. The information available is of uneven detail and quality, and in many cases our assessment is qualitative rather than quantitative. Better information exists about raw material availability, and extraction and production capacity than about possible changes in the fabrication, assembly, use, and repair of new-materials components. Information about the latter remains a "best guess" as the industry remains uncertain about what specific replacement materials will be applied in which automotive components using specific fabrication technology. Also, some estimates could be arrived at with relative ease, while others, for example the cost of energy, would 
include numerous assumptions and are quite difficult to achieve. These assessments are beyond the scope of this report.

A series of tables summarizes the findings of the analysis. Most of the report discusses those entries in the tables that we believe are potentially important to the PNGV program. Given the scenarios' projected gradual penetration of NGVs into the U.S. automobile market, we believe that many of the requirements may be met through the normal activities of firms and markets responding to increased demand for new materials. Our discussion of infrastructure requirements and the effects of substituting materials for steel emphasizes instances in which we believe this accommodation might not occur and might affect the ability of the PNGV program to meet its cost and performance objectives.

\subsection{The Life Cycle of Material Use in Automobiles}

We have identified six stages common to the life cycles of all materials used in automobiles (see Figure 1-1:

- mining or extraction of resources

- $\quad$ smelting or other processing to produce the material frorn the resource

- $\quad$ producing components from the material

- $\quad$ assembling the components into vehicles

- using, maintaining, and repairing the vehicles

- disposing of the vehicle, including any recycling of materials for automotive or other use

A change in materials can have implications at each of the life-cycle stages. Replacement of steel by other materials affects the amount of resource extraction and processing required and could require additional or different types of capital, labor, energy, and other resources required for these processes. Component design or fabrication methods might change, requiring different types of equipment or labor skills and resulting in different kinds of emissions to the environment. The properties of replacement materials could require some differences in how the vehicles are repaired and maintained. Finally, recycling materials other than ferrous or non-ferrous metals from scrap automobiles could require procedures different from the conventional separation technologies now used. Our analysis examined all six stages of the materials life cycle to identify and estimate these requirements, even though available information is mostly for the resource extraction and material production stages. It is important to note that PNGV scenarios implicitly assume that all of these requirements will be met when materials are substituted.

\subsection{Requirements for Material Substitutions}

This analysis estimates changes that will occur under each of five materials replacement scenarios. The change is estimated by comparing the baseline, i.e., requirements absent the PNGV, to projected requirements given the materials demand of NGVs. First, we compare the quantity of raw material needed to meet the demand of the PNGV program to the total available resource. Then, for each of the six stages in a material's life cycle, we have attempted to identify the capital, labor, energy, and material complements (additives) that would be required by and the environmental impacts that might result from materials substitution. The analysis of capital requirements has attempted to determine whether additional capacity would be required, whether technical changes would be necessitated by the substitution, and whether changes in costs and location might occur. We note for labor whether a change in the work force, in terms of its size, skills, and cost, would be required. Because several of the substitute materials are energy-intensive to extract or produce, the availability of inexpensive: 


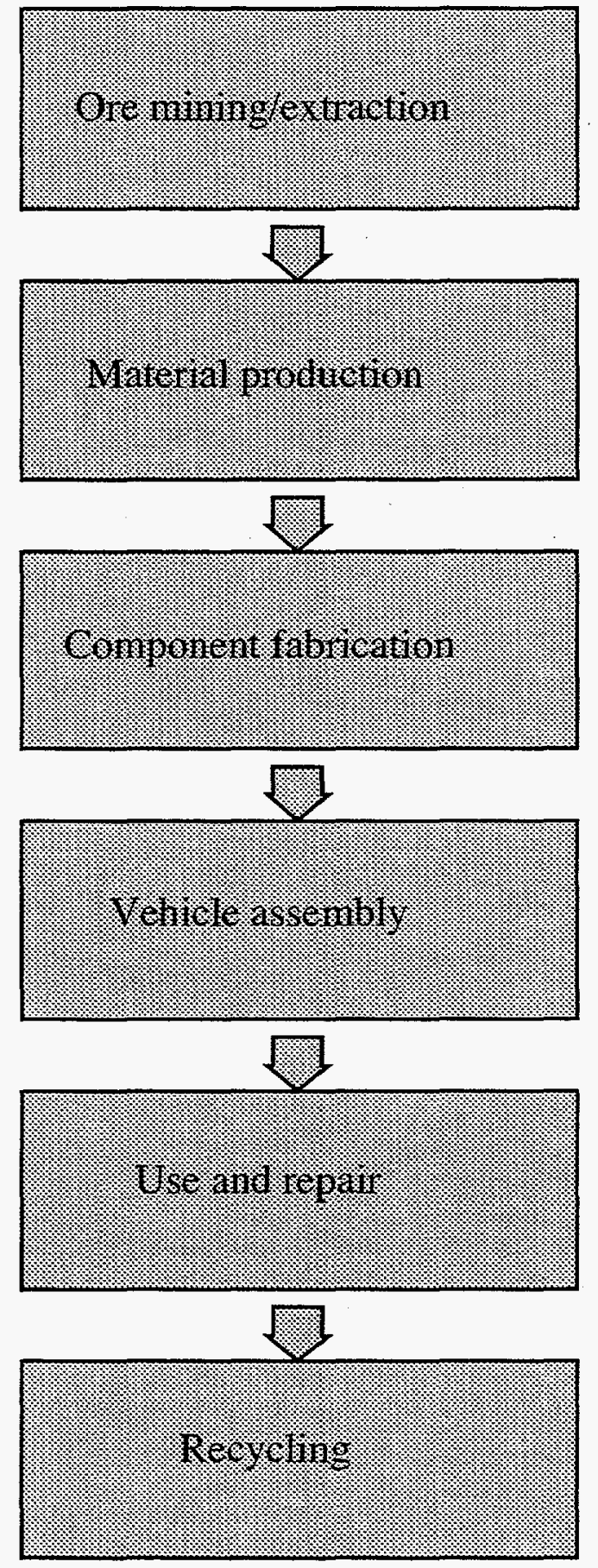

Figure 1-1. Life-cycle stages of automotive materials. 
energy supplies is likely to be an important factor in meeting the cost requirements of the PNGV program and in determining the location of the first two stages of the material life cycle. We have attempted to estimate energy requirements. We have made similar assessments of materials that might be needed to produce or work with the materials targeted by the PNGV program, and of some of the effects that different life cycle stages might have on the environment. We also note other significant requirements, changes, or issues, e.g., the lead time needed to supply the quantity of materials needed, the possible effects of industry structure and health on meeting the requirements, and differences in requirements between early and later stages of NGV penetration into the automobile market.

\subsection{Organization of Report}

The remainder of this introductory chapter provides scenarios for NGV penetration and material substitution that are the basis of the analyses. Chapter 2 discusses the potential effect of replacement materials on the steel industry. Chapters $3,4,5$, and 6 present the changes that would occur if aluminum, magnesium, polymer composites, and lightweight steel, respectively, are substituted for present materials. Each of these chapters begins with a summary of the findings and is organized around a table that provides an overview of the analysis. The tables' columns are each of the six lifecycle stages; the tables' rows are the requirements for raw materials, capital, labor, energy, and material complements, and the resulting environmental effects. Chapter 7 addresses issues associated with recycling NGVs. A concluding chapter summarizes what we believe will be the most important of these changes for the nation's economy and those which may require attention by the PNGV program if they are to occur as needed.

\subsection{Scenarios}

The PNGV has set a goal of reducing vehicle mass by $40 \%$ as part of its strategy to significantly improve fuel economy. Current vehicle weight averages $3,240 \mathrm{lbs}$; the PNGV goal is a reduction in mass to about 1960 pounds. As Table 1-1 shows, this goal implies targets for various vehicle subsystems. Most mass reductions are likely to come from the vehicle body and chassis. Weight savings of this magnitude could be achieved by some combination of material substitution, redesign of all major subsystems (body, powertrain, and chassis), and secondary weight savings (i.e., additional weight savings in subsystems that depend on the total vehicle weight).

\begin{tabular}{|l|c|c|c|}
\hline \multicolumn{4}{|c|}{ Table 1-1. Vehicle mass reduction targets for NGVs } \\
\hline System & $\begin{array}{c}\text { Current Vehicle } \\
\text { (lbs) }\end{array}$ & $\begin{array}{c}\text { PNGV Vehicle } \\
\text { Target (lbs) }\end{array}$ & \% Mass Reduction \\
\hline Body & 1,134 & 566 & 50 \\
\hline Chassis & 1,101 & 550 & 50 \\
\hline Powertrain & 868 & 781 & 10 \\
\hline Fuel/Other & 137 & 63 & 55 \\
\hline Curb Weight & 3,240 & 1,960 & 40 \\
\hline
\end{tabular}

The analysis presented here focuses on material substitution. Several kinds of lightweight materials are being considered by PNGV to meet the mass reduction target. The lightweight materials primarily being considered for substitution are ultra light steel for auto bodies (ULSAB), glass-reinforced polymer composites (GRC), carbon-reinforced polymer composites (CRC), aluminum, and 
magnesium. Except for magnesium, all of these lightweight materials have potential applications in vehicle structures as well as chassis and powertrain components.

Actual selection of materials for NGVs is not anticipated to take place before 1997. At that time, the program will narrow the focus of its technology development to those "candidate" materials and technologies that seem likely to be able to meet PNGV vehicle requirements within the program's established time frame (prototype introduction beginning in 2005).

Because of the present uncertainty about material choices for NGVs, the analysis here develops several scenarios for material substitution, using a "parametric" or "what-if" approach to define the scenarios. Each scenario starts with a current vehicle ("base vehicle") comparable in performance to the NGV, and estimates the maximum extent to which a particular material could replace the base vehicle's current quantity of ferrous material, assuming that other non-ferrous materials contents remain at current levels. Thus, the aluminum scenario estimates the maximum potential substitution of aluminum for ferrous materials but does not adjust the use of other materials in the vehicle. The scenarios developed here thus estimate an upper bound of the amount of each specific lightweight material needed for the NGV. In reality, the NGV would contain a combination of these various lightweight materials, each material appropriate for specific vehicle subsystems. In addition, improved design and secondary weight reductions-factors not considered in the scenarios-would further reduce material requirements.

Table 1-2 shows the material composition of the base vehicle and of five NGVs defined according to the maximum materials substitution scenarios. The term "plastics" in this table includes traditional and advanced polymer composites as well as conventional plastics. The ULSAB scenario considers the replacement of $596 \mathrm{lbs}$ of current carbon-steel body structures with high strength steel which has $50 \%$ less weight, reducing the weight of the vehicle by $298 \mathrm{lbs}{ }^{1}$ For the GRC scenario, 50\% of the baseline vehicle's steel content is replaced by glass-reinforced polymer composites. Composites weighing $653 \mathrm{lbs}$ replace $947 \mathrm{lbs}$ of steel, reducing the baseline vehicle weight by $294 \mathrm{lbs}$. The CRC scenario would substitute carbon-reinforced polymer composites for $50 \%$ of the base vehicle's steel content, just as the GRC scenario does, but because CRCs are lighter than GRCs the substitution would reduce the weight of the base vehicle by $568 \mathrm{lbs}^{2}$

The "Aluminum" scenario assumes that $75 \%$ of current steel and cast iron content is replaced by aluminum, as application of aluminum would extend beyond body structures, particularly for engines. The scenario would replace $818 \mathrm{lbs}$ of steel body structures in the base vehicle with $450 \mathrm{lbs}$ of wrought aluminum, and it would replace engine and other ferrous components with aluminum as well. ${ }^{3}$ This scenario also assumes substitution of $476 \mathrm{lbs}$ of cast aluminum in other components, primarily in chassis and engine applications. Assuming that substituting aluminum for steel and cast iron results in weight savings of $45 \%$, the scenario would reduce the weight of the base vehicle by 757 lbs.

The "Magnesium" scenario assumes that $25 \%$ of current steel, cast iron, and cast aluminum contents would be replaced by magnesium. The weight substitution factors assumed for these materials are $0.33,0.33$, and 0.7 , respectively. It is anticipated that magnesium applications will be limited to non-body structures such as transmission housings, wheels, and seat brackets. However, this scenario also includes substituting magnesium for cast aluminum in some applications such as steering

\footnotetext{
${ }^{1}$ Although stainless steel could be considered for the ULSAB scenario, this option is not as well developed as high strength steel option and is not considered in the analysis.

${ }^{2}$ Weight reductions are based on the assumption that the CRCs and GRCs weigh $60 \%$ less and $31 \%$ less, respectively, than the steel they replace (Sullivan and $\mathrm{Hu} 1995$ ).

${ }^{3}$ Similar aluminum substitution (i.e., $437 \mathrm{lbs}$ ) for body structure and closures is currently being considered attainable for the Ford Taurus/Sable-based aluminum-intensive vehicle using the unibody structure (PNGV 1995).
} 


\begin{tabular}{|l|r|r|r|r|r|r|}
\hline \multicolumn{7}{|c|}{ Table 1-2. Material composition scenarios for PNGV infrastructure: Maximum substitution of } \\
individual materials (lbs)
\end{tabular}

Note: Bold numbers within parenthesis indicate changes in composition from the base vehicle

components. In the PNGV workshop on chassis materials held in early 1996, participants identified components weighing approximately $100 \mathrm{lbs}$ as having potential for magnesium applications. Major components considered for magnesium application included, for example, lower control arms, gear housing assembly, and wheels. As shown in Table 1-2, substituting magnesium for $25 \%$ of ferrous and cast aluminum contents will require an additional $216 \mathrm{lbs}$ of magnesium, resulting in a $390-\mathrm{lb}$ reduction in the total weight of the base vehicle.

The weight reductions presented in Table 1-2 for the individual scenarios are not additive across scenarios because each scenario may substitute its lightweight material for the same ferrous content of the baseline vehicle. Table 1-3 shows two plausible scenario combinations (i.e., "AluminumIntensive" and "Composite-Intensive") for NGVs, indicating how the substitution of various lightweight materials in combination could meet the PNGV target of a $40 \%$ weight reduction. ${ }^{4}$ Under the aluminum-intensive vehicle scenario, $75 \%$ of ferrous steel content of the base vehicle is replaced by various lightweight materials as follows: $50 \%$ by aluminum, $10 \%$ by magnesium, $10 \%$ by carbonreinforced polymer composites, and $5 \%$ by glass-reinforced polymer composites. In addition to primary weight reduction due to the substitution of lightweight materials, there will be secondary weight reductions. Secondary weight reductions occur when reduction in the weight of vehicle subsystems allow additional weight savings in other vehicle subsystems that support them. The potential for secondary weight reduction is estimated to be 5-7\% of the vehicle's weight for each $10 \%$ reduction in primary weight. The aluminum-intensive vehicle scenario assumes that secondary weight reductions would yield a $45 \%$ reduction (by weight) in the use of non-ferrous materials in the

${ }^{4}$ These combination scenarios are hypothetical and intended only to show how PNGV goals can be met. They do not serve as the basis of the analysis. 
base vehicle (assuming that the remaining $25 \%$ of the original ferrous content includes the effect of secondary weight savings). Under the assumptions in the scenario, secondary weight savings

\begin{tabular}{|c|c|c|c|}
\hline Material & Base Vehicle & Aluminum-Intensive & Composite-Intensive \\
\hline Carbon Steel & 1,526 & $\begin{array}{r}382 \\
(-1,144)\end{array}$ & $\begin{array}{r}382 \\
(-1,144)\end{array}$ \\
\hline HS Steel & 369 & $\begin{array}{r}92 \\
(-277)\end{array}$ & $\begin{array}{r}92 \\
(-277)\end{array}$ \\
\hline Cast Iron & 350 & $\begin{array}{r}88 \\
(-262)\end{array}$ & $\begin{array}{r}88 \\
(-262)\end{array}$ \\
\hline Cast Aluminum & 178 & $\begin{array}{r}265 \\
(+87)\end{array}$ & $\begin{array}{r}262 \\
(+84)\end{array}$ \\
\hline Wrought Aluminum & $\overline{52}$ & $\begin{array}{r}479 \\
(+\mathbf{4 2 7}) \\
\end{array}$ & $\begin{array}{r}77 \\
(+25) \\
\end{array}$ \\
\hline Plastics & 342 & $\begin{array}{r}350 \\
(+8)\end{array}$ & $\begin{array}{r}573 \\
(+231)\end{array}$ \\
\hline Magnesium & 5 & $\begin{array}{r}77 \\
(+72) \\
\end{array}$ & $\begin{array}{r}76 \\
(+71) \\
\end{array}$ \\
\hline Other Materials & $\overline{418}$ & $\begin{array}{r}230 \\
(-188)\end{array}$ & $\begin{array}{r}167 \\
(-251)\end{array}$ \\
\hline Total & 3,240 & $\begin{array}{r}1,966 \\
(-1,274) \\
\end{array}$ & $\begin{array}{r}1,717 \\
(-\mathbf{1}, \mathbf{5 2 3}) \\
\end{array}$ \\
\hline
\end{tabular}

NOTE: Bold numbers within parenthesis indicate changes in composition from the base vehicle

calculated in this manner would be equal to about $50 \%$ of primary weight savings from the substitution of aluminum in body structures (e.g., if $500 \mathrm{lbs}$ of "primary weight" is eliminated, $250 \mathrm{lbs}$ of "secondary weight" savings could occur also). The amount of additional wrought aluminum (above baseline use) in the scenario is calculated based on the quantity required for body structures. The estimated final weight of the aluminum-intensive vehicle is $1966 \mathrm{lbs}$, which is close to the PNGV vehicle target total weight of 1960 lbs.

As in the aluminum-intensive NGV scenario, the "Composite-Intensive" NGV would replace $75 \%$ of the base vehicle's ferrous content with other materials. However, the substitutions would rely more on carbon-reinforced polymer composites as follows: $40 \%$ of the ferrous materials would be replaced by carbon-reinforced polymer composites, $20 \%$ by aluminum, $10 \%$ by magnesium, and $5 \%$ by glassreinforced polymer composites. Replacing ferrous materials with carbon-reinforced composites offers a greater weight savings than using aluminum as the replacement material because CRCs weigh only $40 \%$ of the ferrous materials they replace. This larger weight reduction offered by carbonreinforced composites, in tum, allows a $60 \%$ secondary weight reduction in the base vehicle's original non-ferrous materials, compared to the $45 \%$ assumed under the aluminum-intensive vehicle scenario above. Distribution of additional aluminum between wrought and cast is similar to the distribution in the base vehicle. Total weight of the composite-intensive vehicle is estimated to be $1717 \mathrm{lbs}$, a reduction of $1523 \mathrm{lbs}(47 \%)$ from the base vehicle weight. This weight reduction shows that a $50 \%$ PNGV target for the composite-intensive vehicle can be obtained. 
As discussed earlier, we examine the infrastructure requirements for NGVs' maximum potential use of specific lightweight materials. These estimates are based on the product of additional quantity of lightweight material required per vehicle (Table 1-2), and projections of annual sales volume of new light duty vehicles and penetration rates of NGVs. Projected vehicle sales by year are provided in Table 1-4. Light duty vehicles include passenger cars, class 1 light duty trucks, and class 2 light duty trucks. Total new light duty vehicle sales estimates are based on projections by the Energy Information Administration (EIA 1996). Although initial NGV prototypes are targeted at mid-size sedans, actual production of NGV is anticipated to include all light duty vehicles. Material composition of all light duty vehicles is assumed to correspond to average material composition of a domestic automobile considered here. We assume that initial production volumes of NGVs are limited

\begin{tabular}{|c|c|c|c|c|c|c|}
\hline \multirow[b]{3}{*}{ Year } & \multicolumn{3}{|c|}{ High Case } & \multicolumn{3}{|c|}{ Low Case } \\
\hline & \multicolumn{2}{|c|}{$\begin{array}{l}\text { Vehicle Sales } \\
(1000 \mathrm{~s})\end{array}$} & \multirow[t]{2}{*}{$\begin{array}{c}\text { Market } \\
\text { Share }(\%)\end{array}$} & \multicolumn{2}{|c|}{$\begin{array}{l}\text { Vehicle Sales } \\
(1000 \mathrm{~s})\end{array}$} & \multirow[t]{2}{*}{$\begin{array}{c}\text { Market } \\
\text { Share }(\%)\end{array}$} \\
\hline & Autos & $\begin{array}{l}\text { Light } \\
\text { Trucks }\end{array}$ & & Autos & $\begin{array}{l}\text { Light } \\
\text { Trucks }\end{array}$ & \\
\hline 2006 & 0 & 0 & 0.0 & 0 & 0 & 0 \\
\hline 2007 & 9 & 17 & 0.1 & 0 & 0 & 0 \\
\hline 2008 & 29 & 22 & $\overline{0.3}$ & $\overline{0}$ & 0 & $\overline{0}$ \\
\hline 2009 & 58 & 45 & 0.6 & 0 & 0 & 0 \\
\hline 2010 & 97 & 75 & 1.0 & $\overline{0}$ & $\overline{0}$ & 0 \\
\hline 2011 & 151 & 118 & 1.6 & 0 & 0 & 0 \\
\hline 2012 & $\overline{236}$ & 184 & 2.4 & $\overline{0}$ & 0 & $\overline{0}$ \\
\hline 2013 & 370 & 290 & 3.7 & $\overline{49}$ & 39 & 0.5 \\
\hline 2014 & 579 & $\overline{455}$ & 5.8 & 110 & 86 & 1.1 \\
\hline 2015 & 904 & 709 & 9.0 & 169 & 133 & 1.7 \\
\hline 2016 & 1325 & 1024 & 13.0 & 212 & 164 & 2.1 \\
\hline 2017 & 1760 & 1338 & 17.0 & 266 & 202 & 2.6 \\
\hline 2018 & 2208 & 1651 & 21.0 & 332 & 248 & 3.2 \\
\hline 2019 & 2669 & 1964 & 25.0 & 415 & 305 & 3.9 \\
\hline 2020 & $\overline{3144}$ & $\overline{2275}$ & 29.0 & 517 & $\overline{374}$ & 4.8 \\
\hline 2021 & 3710 & 2641 & 33.7 & 64 & 458 & 5.8 \\
\hline 2022 & 4293 & 3005 & 38.4 & 799 & 559 & 7.1 \\
\hline 2023 & 4893 & 3368 & 43.1 & 989 & 680 & 8.7 \\
\hline 2024 & 5511 & 3728 & 47.8 & 1219 & 825 & 10.6 \\
\hline 2025 & 6146 & 4087 & 52.5 & $14 \overline{496}$ & $\overline{995}$ & 12.8 \\
\hline 2026 & 6731 & 4398 & 56.6 & 1827 & 1196 & 15.4 \\
\hline 2027 & 7086 & 4550 & 58.7 & 2218 & 1424 & 18.4 \\
\hline 2028 & 7294 & $\overline{4601}$ & 59.5 & $2 6 \longdiv { 7 4 }$ & 1686 & 21.8 \\
\hline 2029 & 7444 & 4611 & 59.8 & 3198 & 1981 & 25.7 \\
\hline 2030 & 7880 & 4318 & 60.0 & 3939 & 2159 & 30.0 \\
\hline
\end{tabular}

to the domestic market only and are within the range for the introduction of new models and that there will be no significant obstacles in the provision of infrastructure to supply NGVs.

In the high-penetration case, NGVs account for $0.1 \%$ of U.S. light-duty vehicle production in 2007 and increase to $60 \%$ by 2030 . This scenario is a modified version of the mid-case scenario 
established for the "Car Talk" (Resolve, Inc. 1995). Compared with historical experience of introducing radical new automotive technologies such as front wheel drivetrain and weight reductions, the high-penetration case is relatively moderate. For example, the U.S. market share of front-wheel drivetrain vehicles increased between 1976 and 1992 from virtually 0 to $80 \%$ of new passenger cars. NGV production would increase from 9,000 automobiles and 7,000 light trucks in 2007 to 7,880,000 automobiles and 4,318,000 light trucks in 2030.

In the low-penetration case the introduction of NGVs is delayed until 2013, when they account for $0.5 \%$ of production. NGVs account for $30 \%$ of new vehicles by 2030 . In the low-penetration case, NGV market share during the first six years of their introduction exceeds that for the highpenetration case, but the rate of penetration then would slow. NGV production would increase from 49,000 autos and 39,000 light trucks in 2013 to 3,939,000 autos and 2,159,000 light trucks in 2030 . This case is similar to the market share of diesel cars in France during the last 16 years (1973-1989).

Estimates of the total amount of lightweight materials required by NGVs in different years are shown in Table 1-5. We have adjusted requirements for lightweight materials to account for likely fuel economy improvements in new vehicles (referred to as base vehicle here) in the absence of NGVs. We assume an increase of $0.6 \%$ per year in fuel economy of the baseline vehicle during the PNGV penetration period (EIA 1996). Historical data suggest that a $0.2 \%$ annual reduction in the total vehicle weight will achieve the $0.6 \%$ per year increase in fuel economy (Curlee et al. 1994). ${ }^{5}$ Future reductions in total weight of the base vehicle are assumed to result from materials substitutions that maintain the current proportional use per vehicle of that material-aluminum, glass-reinforced composites, and magnesium. Increases in the contents of lightweight materials depend on the replacement factors for the substitution of lightweight materials for ferrous materials, which are assumed to be the same as discussed above for the NGVs. It is estimated that the base vehicle in 2030 will contain about $634 \mathrm{lbs}$ less ferrous materials, but $149 \mathrm{lbs}$ and $259 \mathrm{lbs}$ more of aluminum and plastics, respectively.

Table 1-5 reports the estimates of material requirements in the form of a range. The lower- and upper-end values correspond to the low and high penetration rates of NGVs (Table 1-4). Reduction in ferrous content due to substitution of lightweight materials is also shown in Table 1-5. Our analysis of the effects on the steel industry is based on the "Aluminum" scenario in which the greatest reduction in demand for steel occurs. During the early years of PNGV, the lightweight material requirements are low because of the low penetration rates assumed for NGVs in the automobile market. Lightweight material requirements are highest for glass-reinforced composites during most of the period-reaching a level of more than 2 million metric tons per year by the year 2030 . Although the baseline vehicle and NGVs in the aluminum scenario both have more cast aluminum than wrought aluminum, the increase above baseline for cast aluminum is $267 \%$, while for wrought aluminum it is $865 \%$ (see Table 1-2). This comparatively large increase in wrought aluminum explains why the estimated PNGV requirements for wrought aluminum are higher than for cast aluminum (see Table 1-5). Among ferrous materials used in the baseline vehicle, carbon steel would experience the greatest reduction in demand (annually, 4 million metric tons less by the year 2030). However, percentage reductions (on a per vehicle basis) are the same for each type of ferrous material.

\footnotetext{
${ }^{5}$ Historical data for the period 1976-1993 indicate that there has been almost 52\% improvement in the fleet fuel economy (i.e., $16.1 \mathrm{mpg}$ to $24.5 \mathrm{mpg}$ ) with a $17 \%$ reduction in the average weight of U.S.-built vehicles (i.e., $3761 \mathrm{lbs}$ to $3124 \mathrm{lbs}$ ) (Curlee et al. 1994).
} 


\begin{tabular}{|c|c|c|c|c|c|c|}
\hline \multicolumn{7}{|c|}{$\begin{array}{l}\text { Table 1-5. Lightweight material requirements and reduction in ferrous materials associated with } \\
\text { maximum potential material substitution for PNGV, 2007-2030 (figures in '000 metric tons) }\end{array}$} \\
\hline MATERIAL & 2007 & 2010 & 2015 & 2020 & 2025 & 2030 \\
\hline \multicolumn{7}{|l|}{ Supply Increase } \\
\hline High strength steel & $\overline{0-2}$ & $\overline{0-23}$ & $41-219$ & $\overline{121-734}$ & $337-1386$ & $826-1652$ \\
\hline Cast aluminum & $0-3$ & $\overline{0-34}$ & $57-303$ & $162-981$ & $434-1784$ & $1021-2043$ \\
\hline Wrought aluminum & $0-3$ & $\overline{0-34}$ & $59-317$ & $173-1053$ & $479-1967$ & $1160-2321$ \\
\hline $\begin{array}{l}\text { Glass-reinforced } \\
\text { polymer composites }\end{array}$ & $0-4$ & $0-42$ & $69-368$ & $189-1148$ & $487-1999$ & $1092-2184$ \\
\hline $\begin{array}{l}\text { Carbon-reinforced } \\
\text { polymer composites }\end{array}$ & $0-3$ & $0-30$ & $52-278$ & $154-934$ & $429-1763$ & $1051-2101$ \\
\hline Magnesium & $\overline{0-2}$ & $0-17$ & $30-158$ & $87-529$ & $243-997$ & $594-1188$ \\
\hline \multicolumn{7}{|l|}{ Demand Reduction } \\
\hline Carbon steel & $0-8$ & $0-75$ & $122-655$ & $338-2052$ & $875-3596$ & $1977-3955$ \\
\hline High strength steel & $0-2$ & $\overline{0-18}$ & $30-159$ & $82-497$ & $212-871$ & $479-958$ \\
\hline Cast iron & $0-2$ & $0-17$ & $28-150$ & $77-470$ & $200-823$ & $452-905$ \\
\hline
\end{tabular}

Note: Changes in material requirements are relative to the base vehicle demand. 


\section{STEEL}

\subsection{Findings}

By the year 2030, NGV material substitution could reduce annual demand for iron ore by 9,408 thousand tons (or $12 \%$ below current levels), for sheet steel by 4,913 thousand tons (or 5.5\%), for cast iron by 905 thousand tons (or 6.5\%).

Because the domestic iron ore industry is totally dependent on the steel industry for sales, it is likely that NGVs will hurt the industry unless its growth can be sustained with either new steel applications or the development of economical steel production processes. A $1 \%$ average annual reduction in employment would have minimal effects. Energy demand would be reduced by 18 trillion Btus, the equivalent to the annual U.S. energy consumption of 55,000 people. More than $75 \%$ of this reduction of energy will be in the form of natural gas.

Among consumer products manufacturing industries, the automotive industry is the largest steel consumer, purchasing about 15\% of U.S. steel production (Samways 1996, Samways 1995, Sawinski 1995). Only integrated steel production facilities are capable of supplying the automobile industry because of their unique processing capabilities; however, by the year 2000 cost-efficient minimills will replace about $20 \%$ of current steel production capacity . Although this suggests that the industry as a whole would not be seriously affected by NGVs, steel industry employment-already declining because of increases in automation and productivity - will be reduced by $7.5 \%$ by 2030 as a result of NGVs. Energy demand will be reduced by 78 trillion Btus, or $6.5 \%$ of the total energy used for current steel shipments. Reduction in demand for steel due to NGVs will reduce the steel industry's carbon dioxide emissions by $6.4 \%$ and its particulate emissions by $6.7 \%$.

At the component fabrication stage, job losses in the foundry and stamping industries would occur. A $6.5 \%$ reduction in employment over a period of 22 years would have minimal effects on the foundry industry. High demand for capacity in the stamping industry could minimize employment declines there. Energy demand for auto part stamping and iron castings would be reduced by 21 trillion BTUs and 29 trillion BTUs, respectively, by 2030.

No estimates of loss of capital investment for vehicle assembly are available, but losses will be lessened by the gradual penetration of NGVs. The welding industry would be adversely affected by NGV penetration.

\subsection{Baseline and NGV Demand: Material Input}

Currently available domestic iron ore is in the form of magnetite, which contains a lower content of iron than ore found outside the U.S. The iron ore is concentrated by sintering and is pelletized before shipment. Less than $5 \%$ of total ore is used in the direct form for iron making and about 14$20 \%$ of mined ore is used for steel making. We assume the following yields in the production of steel from iron ore:

1.6 metric tons of iron ore yield 1 metric ton of pig iron,

0.83 metric ton of pig iron yields 1 metric ton of raw steel, and

1.22 metric tons of raw steel yield 1 metric ton of steel sheet.

NGV material substitution could reduce demand for steel by 5404 thousand metric tons and demand for cast iron by 995 thousand metric tons. Demand for iron ore, therefore, would be reduced by 10,349 thousand tons annually by the year 2030 . U.S. consumption of iron ore is estimated to be 85.8 million metric tons in 1995 (USGS 1996c). The PNGV would result in a $12 \%$ reduction in current consumption of iron ore. 
At present consumption rates, known world iron reserves are sufficient to meet world demand well beyond the 21st century (USGS 1996c). Increased availability of domestic iron ore that results from decreased demand from the automotive industry will not affect the world iron ore market. Lower grade ores and higher production cost will prevent the domestic iron ore industry from competing effectively in the world market.

\subsection{Ore Mining/Extraction}

U.S. iron ore production has increased proportional to increases in crude steel production since the early 1990s. The U.S. produced an estimated 68.2 million metric tons of iron ore in 1995, an increase of $6 \%$ from its 1994 level. The U.S. steel industry consumes more than $98 \%$ of domestically mined iron ore. Additionally, the U.S. net imports of iron ore have risen during the early 1990s providing about $18 \%$ of the material consumed in 1995 (USGS 1996d). Australia and Brazil are the leading exporters of iron ore. World production of iron ore in 1995 was 1,100 million metric tons.

The domestic iron ore industry is totally dependent on the steel industry for sales. It is difficult for the U.S. to compete elsewhere in the world iron ore market because of the country's declining ore grades, the inland location of its mines, and high labor and energy costs. It is thus likely that NGVs will hurt the U.S. iron ore industry unless the growth of the industry could be sustained with either new steel applications or the development of economical steel production processes such as directreduced iron (DRD) and non-coke oven oriented COREX production technology (USGS 1996d).

The U.S. iron ore industry is located mainly in the Great Lakes region, i.e., Michigan and Minnesota. Smaller production occurs in California, New Mexico, South Dakota, Texas, and Utah. In 1995, iron ore was produced by 16 companies, nine of which accounted for $98.8 \%$ of all domestic production (USGS 1996c). The industry employs roughly 7,000 employees with an average production output of 4.3 metric tons of ore per hour per worker (USGS 1996d). A $12 \%$ reduction in iron ore demand due to NGVs would thus cause a reduction of 840 employees by the year 2030 , less than $1 \%$ average annual rate of reduction. The effect on the labor market would be thus minimal, particularly in high growth industry areas such as Michigan, Minnesota, and California. There will be a need for training to adapt the available skills in the iron ore industry to the high growth industries. Although overall impacts are estimated to be small, there may be significant localized impacts (both direct as well as indirect, which are not considered here) due to highly concentrated nature of the U.S. iron ore industry.

Assuming that 1.73 million Btus are required to prepare a metric ton of iron ore (Gaines 1996) and that replacement materials will displace 10,349 thousand metric tons of iron ore in vehicles by the year 2030 , energy demand for iron ore production will be reduced by 18 trillion Btus. More than $75 \%$ of this reduction of energy will be in the form of natural gas. The reduction in energy use is equivalent to about the annual U.S. energy consumption of 55,000 people.

Iron ore mining does not engender much environmental concern. Tailings remaining after concentration of iron ore are silica, which are inert in nature. Other significant waste generated is overburden, estimated to be 5.6 metric tons per metric ton of usable ore (USGS 1996d).

\subsection{Material Production}

This life cycle stage of steel includes the production of pig iron, raw steel, and sheet steel. Raw steel is manufactured either in integrated mills or minimills. In integrated mills, iron ores are smelt to crude liquid iron (known as "pig iron") in blast furnaces, and then the pig iron is refined with some scrap in basic oxygen furnaces, producing liquid steel. Minimills, on the other hand, utilize electric arc furmaces to melt raw materials-primarily scrap-to produce steel. Cast iron is produced by melting 
a mixture of steel scrap, cast iron scrap, pig iron, and alloys in a cupola furnace; only a small percentage of cast iron is produced in electric furnaces.

To determine how demand for steel and cast iron would be affected by PNGV replacement materials, we use the yields described in the previous section and assume 0.5 metric ton of pig iron is used per metric ton of cast iron. Table 2-1 shows the maximum reduction in annual demand for steel (in its various forms) that would result from NGVs in 2030. Percentage reductions in demand for steel are small given the time period over which they will occur.

\begin{tabular}{|l|c|c|c|c|}
\hline \multicolumn{5}{|c|}{ Table 2-1. Maximum steel products replaced annually by NGVs by 2030 } \\
\hline & Pig iron $^{1}$ & Raw steel & Sheet steel & Cast iron \\
\hline $\begin{array}{l}\text { Reduction in demand } \\
(1,000 \text { metric tons) }\end{array}$ & 5,970 & 6,593 & 5,404 & 995 \\
\hline $\begin{array}{l}\text { Percent reduction in } \\
\text { current (1995) levels }\end{array}$ & & & & \\
\hline
\end{tabular}

${ }^{1}$ This figure represents the upper limit because some raw steel will be produced using scrap rather than pig iron.

${ }^{2}$ These percentage are total reductions would occur over period between 2007 and 2030 . Reductions are relative to current production for pig iron and raw steel and relative to current shipments for sheet steel.

Source: USGS 1996. "Iron and Steel: Mineral Commodity Summaries," Reston, VA, January.

The U.S. steel industry, despite its impressive size (ranked third in the world, preceded only by the Commonwealth of Independent States and Japan), began declining in the mid-1970s and suffered a devastating depression between 1982 and 1986. Anemic market growth, expensive labor, increased production costs, and stagnant prices weakened many manufacturers in the industry. In addition, the proliferation of foreign competition and the popularity of substitute materials such as plastics and aluminum, gouged industry profits. After peaking in 1978 at over 151 million metric tons, U.S. steel production slipped to less than 99 million metric tons in 1991 (Sawinski 1995).

Since the early 1990 s, new production techniques and facilities, as well as increased automation, have helped U.S. steelmakers to be among the most productive in the world. Minimills, or non-integrated facilities, have begun to gain market share (e.g., almost $40 \%$ of total U.S. steelmaking in 1994) because their capital cost requirements are lower than traditional integrated mills (i.e., $\$ 450 /$ metric ton vs $\$ 1,800 /$ metric ton [Sawinski 1995]). Productivity in the industry has risen. In the 1970 s, 10.2 person hours were required to produce one metric ton of steel; in 1990 only 3.6 person hours were needed; and in 1993 a metric ton of steel was produced with only 2.7 person hours.

Since the early 1990 s, U.S. production and shipments have been increasing at a constant rate of $1.035 \%$ and $1.0725 \%$ per year, respectively. The U.S. shipped about 115.5 million metric tons of steel products in 1995 (USGS 1995a). However, the industry continues to maintain huge trade deficits, particularly with Europe, Asia, and South. Most imports are in the form of semifinished steel for rolling in the United States. The estimated 30 million metric tons of semifinished steel imported in 1995 accounted for $26 \%$ of the apparent consumption of steel products in 1995 (including adjustments for industry stock changes; USGS 1996a).

At present, the largest share (i.e., 25\%) of U.S. steel production is consumed by service and distribution centers that remarket steel to smaller buyers. Among consumer products manufacturing industries, the automotive industry is the largest steel consumer, purchasing about $15 \%$ of U.S. steel production (Samways 1996, Samways 1995, Sawinski 1995). In 1995, U.S. producers shipped 97.9 million metric tons of steel mill products. 
The U.S. steel industry is at its near-effective capacity (i.e., more than $90 \%$ of estimated capacity), and the industry predicts that as much as 22 million metric tons of capacity (i.e., almost $20 \%$ of current steel production) of cost-efficient minimills will be built by about the year 2000 . The new minimills will replace expensive integrated production facilities (USGS 1996b). Only integrated steel production facilities are capable of supplying the automobile industry because of their unique processing capabilities such as annealing and electrogalvanizing at the finishing stage. NGV-related reduction in demand and the forecasted capacity additions of efficient minimills will make production capacity available to other, non-automotive markets. Growth is forecasted for several other potential markets for steel and the current health of the steel industry is expected to continue. Growing potential markets for steel include commercial and home appliances, and construction." Strong growth (4.5\% per year) in demand forecasted for foreign markets, particularly the Peoples Republic of China and other Asian countries (excluding Japan), will benefit U.S. steel producers (Samways 1996). However, excess available finishing capacity will be difficult to re-utilize as no other industry requires the high quality processing that the automobile industry does.

Total employment in the steel industry (including blast furnaces and steel mills) in 1995 was 171,000 , turning out a similar amount of steel as 500,000 employees did in the 1970s (USGS 1996b). U.S. steel productivity nearly doubled between 1980 and 1993. During the same period, the number of person-hours required to produce a unit of steel plummeted more than threefold. Minimills shipped an average of 827 metric tons per employee during that period, compared with 419 metric tons per worker for integrated producers (Sawinski 1995). The trend toward automation results in less jobs and jobs that require less skilled workers.

Because NGV-related decline in steel production will occur in integrated facilities, a maximum demand reduction of 5,404 thousand metric tons of sheet steel will result in a loss of 12,895 workers or $7.5 \%$ of the present level by the year 2030. (Note that this number includes raw steel and steel mill jobs.) Most of the job losses will occur in the Great Lakes area (i.e., Illinois, Indiana, Michigan, and Ohio). The loss of employment in the industry due to NGVs will exacerbate already declining employment associated with increased productivity in the steel industry. There is a $0.5 \%$ annual decline in jobs in the primary metal industries forecast for the Great Lakes region when NGVs will enter the marketplace (U.S. Department of Commerce 1990). Since the skills required in metal production and advanced materials production are quite different, retraining and skill-building programs will be essential for shifting the lost jobs to the new industry.

Lower demand for raw steel due to NGVs will reduce the steel industry's energy requirements. We estimate that 78 trillion Btus less energy will be required by the steel industry, assuming that 14.2 million Btus of energy is required per metric ton of sheet steel in integrated steel making. More than $60 \%$ of total reduction in energy requirements will be in the form of natural gas. This reduction in energy requirements amounts to about $6.5 \%$ of total energy used for the current steel mill shipments of 97.9 million metric tons. (Total energy used in production of current steel shipments is estimated using the assumption that the ratio of production at integrated facilities and minimills is 60:40.)

${ }^{6}$ Growing potential markets for steel include commercial and home appliances, and construction. Highways look like the most promising application in construction, particularly where sea spray or substantial salting of roads in winter creates severe corrosion conditions. States such as Michigan and New Jersey have been testing stainless steel rebar in bridges for the past several years. Sheet steel based manufactured building is increasing in both industrial and residential construction. In 1994 non-residential use of steel in construction grew by 15 percent over 1993 use. Residential use of steel is also promising. In 1992, 500 homes were built with steel framing. This increased to 40,000 in $1994,80,000$ in 1995 , and is expected to increase to 250,000 homes by 1997 . In addition, steel roofs are gaining popularity (Wilhem 1995). New uses for steel are also being found in automobile manufacturing. Stainless steel is used to make the explosive canisters in airbags, which automakers are now installing in the passenger and rear seats in addition to the driver side. There is also promise for stainless steel fuel tanks and fuel lines (Read 1995). 
The major environmental concern associated with steel making is the emissions during coke production. Assuming a 60:40 production ratio at integrated facilities and minimills, total emissions of carbon dioxide and particulate matter due to steel mill shipments in 1995 are estimated to be about 67 and 0.07 million metric tons, respectively. Reduction in demand for steel due to NGVs will reduce the steel industry's carbon dioxide emissions by $6.4 \%$ and its particulate emissions by $6.7 \%$. Such large reductions in total industry emissions result because integrated facilities produce more carbon dioxide and 10 times more particulate matter than carbon arc minimills (on a "ton by ton" comparison not taking into account emissions from steel scrap used in electric arc steelmaking).

\subsection{Component Fabrication}

This production step includes the manufacturing of automotive parts by casting and stamping. U.S. shipments of steel mill products and iron castings are estimated to be 97.9 and 15.4 million metric tons, respectively in 1995 (USGS 1996a). A reduction in demand of 995 thousand metric tons of cast iron due to NGVs in the year 2030 represents a $6.5 \%$ reduction in the current shipments. Thus, the effect of reduced demand for iron castings on the foundry industry would be minimal over a period of 25 years. Current capacity utilization rate of the motor vehicle parts and accessories industry is estimated to be in the range of $75-80 \%$ (U.S. Department of Commerce 1994). NGVs will reduce demand for sheet metal stampings, resulting in excess stamping capacity. Some excess capacity could be used to meet strong demand in non-automotive applications or could be adapted for stampings of new automotive materials such as high strength steel.

Although job losses in the sheet metal stamping industry could result from NGVs, no estimates are currently available on the industry's current employment level. There will also be a loss of employment in iron and steel foundries due to reduction in demand for cast iron castings from NGVs. Total employment in iron and steel foundries in 1995 is estimated to be 130,000 . A loss of $6.5 \%$ of shipments due to NGVs in the year 2030 will result in a loss of 8,450 workers (USGS 1996a). Most of these job losses will occur in the Great Lakes area, where most of these industries are currently concentrated.

Assuming that 3.9 million Btus of energy are required per metric ton of steel during the auto part stamping process, it is estimated that 383 trillion Btus of energy were consumed for shipments made in 1995. A 5.5\% reduction in shipments due to NGVs would thus lessen energy requirements by 21 trillion Btus. Similarly, 448 trillion Btus of energy were consumed for the 1995 shipments of iron castings (assuming 28.8 million Btus of energy is required per metric ton of iron castings). A savings of 29 trillion Btus annually is estimated by the year 2030 for iron castings.

\subsection{Vehicle Assembly}

The capital investment made for the vehicle assembly of a typical vehicle model life of 8-10 years is generally large. No estimates are currently available on the level of loss of investments due to a shift to lightweight materials. The loss of investments on the assembly line will be considerably lessened by the gradual penetration of NGVs. Because the auto industry is the top market for both arc welding and resistance welding, converting to new materials requiring different assembly methods will adversely affect the welding industry. 



\section{ALUMINUM}

\subsection{Findings}

The findings of this chapter are summarized in Table 3-1. The United States now imports essentially all of its metallurgical bauxite, either as ore, alumina, or aluminum. Producing aluminum from bauxite is electricity-intensive and weight losing, i.e., aluminum weighs one-quarter as much as the bauxite from which it is produced. For these reasons and because domestic availability is limited to more expensive, lower-grade bauxite, there is little incentive to expand aluminum production in the United States. Therefore, the aluminum used in NGVs likely will be produced outside the United States. Employment associated with aluminum production will occur outside the U.S., replacing steel production jobs within the United States.

The average automobile produced in theUnites States in the mid 1990s contains approximately 200 pounds of aluminum (Modern Metals 1994). Under this substitution scenario, NGVs would have 1,156 pounds of aluminum. NGVs would require an additional $2,181-4,364$ thousand metric tons of aluminum by 2030 , depending on the NGV penetration rate. This demand would require an 11-23\% increase above 1995 world production levels. It is anticipated that the secondary aluminum production will continue to contribute a significant share of its total production with the widespread recyclinge of aluminum used in several applications beyond the automobile industry. Estimated generating capacity additions and energy and environmental impacts provide here the maximum likely impacts due to NGVs. In addition to this capacity increase, some existing capacity may have to be replaced to take advantage of lower cost, innovative sheet production technologies. Such innovations are considered necessary to meet the cost-per-vehicle goals of the PNGV. The production of aluminum for NGVs will require five times more energy than the production of steel for baseline vehicles.

Aluminum automobile components can be made using a variety of well-established technical processes, including casting, stamping, and extrusion. Most of the aluminum components now in use are in the form of castings. The casting and stamping processes for aluminum differ from those for steel; these should not be technically difficult for the automobile industry or its workforce to adopt, but the adoption of stamped aluminum components would require use of new stamping equipment designed for this material. Extrusion holds potential to allow simplification of component and vehicle design. However, the automobile industry and its component suppliers have little experience with this method of metal forming. The processes for joining aluminum components can differ from those for joining steel ones, although this depends on the component and vehicle designs. These should not require substantially greater skill levels to use but, again, they can require the use of new equipment.

The increased use of aluminum, especially in body panels and frames, will require some changes in vehicle repair skills. These new skills might be in short supply during the early years of NGV market penetration, but they would become more available as NGVs become a larger share of the nation's vehicle fleet. To offset higher material costs-aluminum is more expensive than steel-NGV designs will likely include more complex parts that require less assembly. Repairing accident damage, consequently, could be more costly, making automobile insurance, and therefore, vehicle ownership more costly.

\subsection{Baseline and NGV Demand: Material Input}

The average automobile produced in the U.S. in the mid 1990s contains approximately 200 pounds of aluminum (Modern Metals 1994). Aluminum is produced in a two-step process that extracts 
Table 3-1. Issues associated with aluminum use in NGVs

\begin{tabular}{|c|c|c|c|c|c|c|}
\hline \multirow[b]{2}{*}{ Requirement } & \multicolumn{6}{|c|}{ Life-cycle Stage } \\
\hline & $\begin{array}{l}\text { ore mining/ } \\
\text { extraction }\end{array}$ & $\begin{array}{l}\text { material } \\
\text { production }\end{array}$ & $\begin{array}{l}\text { component } \\
\text { fabrication }\end{array}$ & vehicle assembly & $\begin{array}{l}\text { vehicle use/ } \\
\text { repair }\end{array}$ & $\begin{array}{l}\text { recycling/ } \\
\text { disposal }\end{array}$ \\
\hline $\begin{array}{l}\text { Mineral/ } \\
\text { material supply }\end{array}$ & $\begin{array}{l}\text { ample supply } \\
\text { outside the U.S. }\end{array}$ & $\begin{array}{l}\text { affected by } \\
\text { availability of } \\
\text { mined bauxite }\end{array}$ & na* & na & na & na \\
\hline \multicolumn{7}{|l|}{ Capital/equipment } \\
\hline capacity & $\begin{array}{l}\text { additonal } 8,700 \text { to } \\
17,400 \text { tmt }^{* *} \\
\text { needed }\end{array}$ & $\begin{array}{l}<1 \% \text { annual } \\
\text { increase in capacity } \\
\text { (total of } 11 \text { to } 23 \% \\
\text { increase) to meet } \\
\text { demand }\end{array}$ & $\begin{array}{l}\text { new fabrication } \\
\text { capacity required }\end{array}$ & $\begin{array}{l}\text { no significant } \\
\text { change in capital } \\
\text { equipment }\end{array}$ & $\begin{array}{l}\text { two sets of repair } \\
\text { equipment needed }\end{array}$ & no change \\
\hline technical change & none required & none required & $\begin{array}{l}\text { complex parts and } \\
\text { alternative } \\
\text { fabrication methods } \\
\text { (e.g., extrusion, } \\
\text { stamping) may be } \\
\text { needed to achieve } \\
\text { performance, cost } \\
\text { objectives; } \\
\text { automotive industry } \\
\text { has little experience } \\
\text { with alternative } \\
\text { production methods }\end{array}$ & $\begin{array}{l}\text { change in assembly } \\
\text { method, but no } \\
\text { difficulty projected }\end{array}$ & $\begin{array}{l}\text { repair methods } \\
\text { available }\end{array}$ & $\begin{array}{l}\text { sufficient time } \\
\text { exists for developing } \\
\text { and implementing } \\
\text { any necessary } \\
\text { changes }\end{array}$ \\
\hline $\cos t$ & na & $\$ 11.5-\$ 23$ billion & na & na & $\begin{array}{l}\text { ownership costs } \\
\text { higher due to } \\
\text { higher insurance } \\
\text { costs that result } \\
\text { from repairing } \\
\text { complex parts } \\
\end{array}$ & no change \\
\hline location & outside the U.S. & $\begin{array}{l}\text { investment likely } \\
\text { outside the U.S. }\end{array}$ & no change & no change & na & no change \\
\hline
\end{tabular}

\footnotetext{
* The entry "na" means not applicable, or not addressed for lack of data or because it is beyond the scope of the report.

${ }^{* *}$ tmt $=$ thousand metric tons
} 
Table 3-1. Issues associated with aluminum use in NGVs (continued)

\begin{tabular}{|c|c|c|c|c|c|c|}
\hline \multirow[b]{2}{*}{ Requirement } & \multicolumn{6}{|c|}{ Life-cycle Stage } \\
\hline & $\begin{array}{l}\text { ore mining/ } \\
\text { extraction }\end{array}$ & $\begin{array}{l}\text { material } \\
\text { production }\end{array}$ & $\begin{array}{l}\text { component } \\
\text { fabrication }\end{array}$ & vehicle assembly & $\begin{array}{l}\text { vehicle use/ } \\
\text { repair }\end{array}$ & $\begin{array}{l}\text { recycling/ } \\
\text { disposal }\end{array}$ \\
\hline \multicolumn{7}{|c|}{ Labor/employment } \\
\hline quantity & $\begin{array}{l}\text { proportional to } \\
\text { increase in demand }\end{array}$ & $\begin{array}{l}\text { proportional to } \\
\text { increase in demand }\end{array}$ & no change & $\longdiv { \text { no change } }$ & no change & $\begin{array}{l}\text { necessity of hand } \\
\text { disassembly may } \\
\text { increase cost } \\
\text { significantly } \\
\end{array}$ \\
\hline skill level & no change & no change & $\begin{array}{l}\text { new, easy-to-acquire } \\
\text { skills }\end{array}$ & $\begin{array}{l}\text { new, easy-to-acquire } \\
\text { skills }\end{array}$ & little or no change & no change \\
\hline location & $\begin{array}{l}\text { continue to be } \\
\text { outside the U.S. }\end{array}$ & $\begin{array}{l}\text { aluminum } \\
\text { production jobs } \\
\text { outside the U.S. } \\
\text { will replace steel } \\
\text { production jobs in } \\
\text { the U.S. } \\
\end{array}$ & no change & na & na & na \\
\hline \multicolumn{7}{|l|}{ Energy } \\
\hline type & all forms & electricity & $\overline{\text { na }}$ & na & na & no change \\
\hline quantity & \multicolumn{2}{|c|}{$\begin{array}{l}5 \text { times more electricity to produce } \\
\text { aluminum for NGVs; } 5-10 \mathrm{GW} \\
\text { generating capacity needed }\end{array}$} & na & na & na & no change \\
\hline $\operatorname{cost}$ & na & na & na & na & na & no change \\
\hline Iocation & $\begin{array}{l}\text { depends on location } \\
\text { of materials }\end{array}$ & $\begin{array}{l}\text { depends on location } \\
\text { of production } \\
\text { capacity }\end{array}$ & na & na & na & no change \\
\hline $\begin{array}{l}\text { Material } \\
\text { complements }\end{array}$ & na & various alloys & na & na & na & $\begin{array}{l}\text { different alloys, } \\
\text { different aluminum } \\
\text { forms, and adhesives } \\
\text { may be problematic }\end{array}$ \\
\hline
\end{tabular}


Table 3-1. Issues associated with aluminum use in NGVs (continued)

\begin{tabular}{|c|c|c|c|c|c|c|}
\hline \multirow[b]{2}{*}{ Requirement } & \multicolumn{6}{|c|}{ Life-cycle Stage } \\
\hline & $\begin{array}{l}\text { ore mining/ } \\
\text { extraction }\end{array}$ & $\begin{array}{l}\text { material } \\
\text { production }\end{array}$ & $\begin{array}{l}\text { component } \\
\text { fabrication }\end{array}$ & vehicle assembly & $\begin{array}{l}\text { vehicle use/ } \\
\text { repair }\end{array}$ & $\begin{array}{l}\text { recycling/ } \\
\text { disposal }\end{array}$ \\
\hline $\begin{array}{l}\text { Environmental } \\
\text { emissions/impacts }\end{array}$ & $\begin{array}{l}\text { bauxite storage } \\
\text { could release up to } \\
70 \text { tmt of partic- } \\
\text { ulates in } 2030 ; \\
\text { equal to } 3 \% \text { of } \\
\text { particulates from } \\
\text { industrial and fuel } \\
\text { combustion pro- } \\
\text { cesses in the U.S. }\end{array}$ & $\begin{array}{l}13-26 \text { tmt of } \\
\text { gaseous fluorides } \\
\text { (66\% additional } \\
\text { particulate } \\
\text { fluorides) and } \\
4,500-9,000 \mathrm{tmt} \\
\mathrm{CO}_{2} \text { by } 2030 ; \\
\text { potlining is } \\
\text { hazardous waste } \\
\text { (cyanide content) }\end{array}$ & na & na & na & unknown \\
\hline
\end{tabular}


alumina from bauxite and then aluminum from alumina. ${ }^{7}$ NGVs would increase aluminum content of automobiles to 1,156 pounds in the high-aluminum scenario. Each NGV, under this scenario, would require 4,624 pounds (or 2.1 metric tons) of bauxite, and the PNGV program demand for bauxite in 2030 would be 8,724 to 17,456 thousand metric tons (Table 3-2).

\begin{tabular}{|l|l|l|l|l|l|l|}
\hline \multicolumn{6}{|c|}{ Table 3-2. Increases in aluminum production and associated requirements to meet NGV } \\
demand.
\end{tabular}

${ }^{2}$ Values are thousand metric tons unless otherwise noted.

${ }^{b}$ Assumes no recycling. Recycling of NGVs could become a significant source of supply in the early $2020 \mathrm{~s}$ in the high penetration scenario, and this would reduce the amount of new smelting capacity required.

Virtually all U.S. bauxite is used for non-metallurgical purposes. The U.S. now imports essentially all of its metallurgical bauxite-either as ore, alumina, or aluminum-from abroad, where higher grade, less expensive bauxite is readily available.

Domestic resources of bauxite are inadequate to meet projected long-term demand--even without additional demand from the PNGV program (Mineral Commodity Summaries: Bauxite and Alumina 1996). Large reserves of bauxite in Australia and elsewhere would be the potential sources to meet the PNGV program demand.

The U.S. has essentially inexhaustible resources of aluminum in material other than bauxite. Although production from these resources - clay, coal waste, oil shale, and other materials-is technically feasible, it is not cost-competitive with aluminum produced from bauxite.

\subsection{Mining/Ore Extraction}

U.S. bauxite production is limited to a few individual firms, so data are scarce. It is unlikely that NGVs would result in any additional domestic mining of bauxite. Bauxite and alumina for NGVs-as for today's vehicles-will be mined outside the United States, primarily for economic reasons.

${ }^{7}$ Converting bauxite to alumina results in a $50 \%$ reduction in weight; converting alumina to aluminum also results in a $50 \%$ reduction in weight. 
During the period 1991-1994, 33\% of the combined bauxite and alumina for U.S. primary aluminum production was imported from Australia; 21\% from Jamaica; 19\% from Guinea; 9\% from Brazil; 3\% from Guyana; 3\% from Suriname; and 12\% from other countries (Mineral Commodity Summaries: Bauxite and Alumina 1996). Therefore, all requirements (capital investment, labor) and effects (environmental) of bauxite mining for NGVs will occur in countries other than the U.S.

Current bauxite mining production is above 110,000 thousand metric tons. The world bauxite mining industry has increased capacity to meet gradual increases in world demand for aluminum (0-4\% annual growth, averaging 3.4\% during 1986-1990), and the bauxite mining industry can be expected to accommodate future growth in this range. A more rapid increase in demand probably could be met if suppliers were confident that the demand would be sustained. Because bauxite mining is essentially entirely an overseas activity, estimates of the investment, employment, and environmental requirements of bauxite mining were not available for this review.

Potential environmental problems arise from mining and shipping bauxite. Bauxite mining typically uses surface mining or open pit mining, with associated impacts of land disturbance (e.g., deforestation), accumulation of overburden and tailings, release of dust, and potential for contamination of groundwater and surface water supplies. The process of unloading bauxite and storing it in bins releases dust. Emission controls can reduce particulate emissions to 0.0005-0.004 $\mathrm{kg}$ per metric ton of ore stored, depending on the control technology used (EPA 1996). If all of the bauxite required by the high-penetration, maximum aluminum scenario were imported into the U.S. as bauxite, it would release $4-70$ thousand metric tons of dust per year at the unloading ports. This compares with 2.41 million metric tons of particulates released from fuel combustion and industrial processes nationally in 1993 (Davis 1995; estimates exclude fugitive dust). Because most bauxite would be processed into alumina or aluminum overseas, and because imports probably would enter at a number of ports, the impact on any individual U.S. port would be far smaller than this.

\subsection{Aluminum Smelting and Production}

The U.S. consumed approximately $34 \%$ of the 19,300 thousand metric tons of aluminum produced in the world in 1995 (Mineral Commodity Summaries: Aluminum 1996). World smelter capacity was estimated at 22,200 thousand metric tons per year in 1995. From 1986-1995, world and U.S. aluminum production increased $17 \%$ and $10 \%$, respectively. However, since 1990, production in the world essentially has been flat and production in the U.S. has declined.

At present, transportation accounts for approximately $28 \%$ of U.S. aluminum consumption (Minerals Yearbook 1994), with the manufacture of cars and light-duty trucks accounting for approximately $40 \%$ of this (calculated from vehicle production reported in (Davis 1995) and $200 \mathrm{lbs}$. aluminum/vehicle). This is about 1,080 thousand metric tons of the 6,500 the U.S. consumed in 1995. U.S. light vehicle production thus consumed $5.6 \%$ of world aluminum production.

NGVs would increase aluminum content of automobiles from the present $230 \mathrm{lbs} / \mathrm{vehicle}$ to $1,156 \mathrm{lbs} /$ vehicle in the high-aluminum scenario (Table 1-2). In 2007 , this would increase aluminum use by only 6 thousand metric tons over what would probably would be used without the PNGV program. However, NGVs would require an additional 2,181-4,364 thousand metric tons of aluminum by 2030 , depending on the NGV penetration rate. This demand would require an 11--23\% increase above 1995 world production levels.

Projections of world aluminum consumption in 2007 and 2030 were not available for comparison. However, for purposes of illustration, an increase of 11-23\% from present levels, over a 23-year period, would be a $0.4-0.9 \%$ annual rate of growth. For comparison, historic annual growth rates in world aluminum production have been $0-3.4 \%$ over the past 1.0 years. Because aluminum use in the base vehicle is also expected to increase, total consumption of aluminum in U.S. automobile 
production would be greater than the increase attributable to NGVs alone. However, world production is also likely to be greater, better accommodating the demand of the maximum aluminum scenario.

Given present excess aluminum smelting capacity in the world market, the aluminum smelting industry probably can accommodate the additional demand for aluminum by NGVs within its normal investment patterns, provided that producers have reasonable expectations that the increased demand would continue. However, additional capacity-above the normal investment pattern-would be required at the outset to utilize lower cost, innovative sheet production technologies. Such innovations are considered necessary to meet the cost-per-vehicle goals of the PNGV. The combined investment for Bayer and smelting production capacity required for NGVs by 2030 is between $\$ 11,480$ and $\$ 22,971$ million (see Table 3-2) depending on NGV penetration rates.

Refining bauxite into alumina-using the Bayer process-requires substantial quantities of thermal energy and caustic chemicals. Resource requirements for refining vary with the grade and source of bauxite ore and with some details of the refining process, but in the mid 1970s the production of two metric tons of calcined alumina (approximately one metric ton of aluminum) required 0.14 metric tons of lime, 5.9-6.6 metric tons of low-pressure steam, 5600-8000 cubic feet of natural gas, and $205 \mathrm{kWh}$ of electricity (Pierce et al. 1984, Gaines 1996). It is likely that the industry has reduced these energy requirements in response to high energy prices since these requirements were estimated. In the mid 1970s, the cost of a Bayer plant was estimated to be on the order of $\$ 568.75$ per annual metric ton of aluminum (original estimate escalated to 1993 dollars through use of GNP price deflator; Pierce et al. 1984).

The capital cost for an aluminum smelter in the mid 1970s was estimated to be on the order of $\$ 3336.92$ / annual metric ton (original estimate escalated to 1993 dollars through use of GNP price deflator) (Pierce et al 1984). Discussions with persons familiar with the aluminum industry suggest that the present cost is probably around $\$ 3600 /$ metric ton in 1995 dollars, and that it probably would be difficult to build a smelter of less than 275,000 metric tons/year, requiring an investment of roughly $\$ 1$ billion. Producing aluminum from alumina requires $10.5-12.0 \mathrm{MWh} / \mathrm{metric}$ ton, although persons familiar with the industry indicate that the most efficient new capacity operates at the high end of this range. Adding the high end of this range to the electricity requirements for the Bayer process yields estimates of 5-10 GW of generating capacity needed to produce the aluminum for NGVS. This energy requirement is five times greater than baseline vehicles' energy requirements. The cost of this generating capacity would vary greatly, depending on the type built (hydroelectric, gas turbine, or coal-fired steam) and its location; no effort has been made to estimate these costs for this study.

The average operating costs per pound of aluminum on the world market averaged $\$ 0.548$ in 1992 (Bird 1993); 32\% of this cost was for alumina, $26 \%$ for electricity, $15 \%$ for labor, and $27 \%$ other; much of the "other" category probably includes the cost of replacing anodes consumed in the electrolytic smelting process. This figure excludes costs of capital, interest, depreciation, new facility start-up, and responses to supply disruption. Given the high proportion of cost attributable to alumina and electricity, any expansion of aluminum smelting capacity will favor locations where alumina is produced (to reduce the cost of transporting weight equal to twice that of the final product) and where large amounts of inexpensive electricity are available. Neither of these conditions favor capacity expansion in the U.S. Indeed, despite a $29 \%$ increase in U.S. aluminum consumption from 1991 and 1995, U.S. aluminum production declined by nearly 19\%, as less-expensive capacity has come online overseas and as the world aluminum market adjusted to changes in the Russian smelting industry. The U.S. imported approximately $30 \%$ of the aluminum it consumed in 1995 . Between 1991 and 1995, 68\% of US aluminum imports came from Canada and 12\% from Russia, with the Russian share increasing during this period.

Historically, aluminum smelting capacity has been developed in conjunction with low-cost hydroelectricity. Although aluminum smelters, with large baseload demands, are likely to be able to 
negotiate price discounts for electricity, over the long term these prices are likely to increase and to be set by the cost of expanding electricity supplies from low-cost fossil fuels. Likely locations for new smelting capacity are Australia, which has large reserves of both high-grade bauxite and inexpensive brown coal; the Middle East, where there is a large quantity of byproduct natural gas; and Canada, which still has large undeveloped hydroelectric resources. ${ }^{8}$

The trend toward importing more aluminum and the likelihood that new production capacity would occur outside the U.S. suggest that much of the aluminum for NGVs will be produced outside the U.S. Aluminum-production jobs, therefore, also will occur outside the U.S., potentially replacing U.S. steel jobs.

Aluminum production, especially the Hall-Heroult process, generates gaseous and particulate pollutants. Among them, fluorides (both gases and particulates) are the most serious. About 1326 thousand metric tons of gaseous fluorides will be emitted by the year 2030, depending on the NGV penetration rate. Particulate fluoride emissions will be an additional $66 \%$ of the total gaseous fluorides emissions. Other pollutants include alumina dust, sulfur dioxide, carbon monixide, and carbon dioxide. It is estimated that emissions of carbon dioxide due to NGVs will be in the range of $4,486-8,977$ thousand metric tons by the year 2030. Other environmental concerns include the spent potlining-the largest volume of solid waste generated by the aluminum smelting process. The waste is considered hazardous because of its cyanide content.

\subsection{Component Fabrication}

The three primary methods of producing components from metal are casting, extrusion, and metalworking (bending, rolling, and stamping). It often is possible to make equivalent parts from a material using alternative methods, and component manufacturers choose among methods based on the quality, performance, or cost of the product. Producing a part via extrusion instead of stamping, for example, involves tradeoffs in component design, material specifications, and the design and use of the equipment that actually produces the component. Each of these factors can affect the final product and its cost.

Most aluminum components in today's automobiles are castings. Only a few "niche" models contain significant proportions of stamped and extruded aluminum. Some automakers plan to introduce more stamped components during the next several years.

Alternative component fabrication processes will be required because traditional methods cannot yet yield components with performance characteristics that match their steel equivalents. For example, persons familiar with the aluminum industry noted that aluminum components produced with conventional die-casting methods have poor structural strength. Advanced die-casting methods can yield improved strength but are more costly because they require longer residence time by the component in the fabrication equipment. Thus the production rate per machine is lower, requiring more machines, changes in production processes, or changes in the layout of the production process to accommodate different throughput rates. The last of these options might involve shifting component fabrication off-site. Any of these options will increase the cost of capital in the short run, perhaps substantially, until the industry learns the most effective ways to adapt its methods to the requirements of producing and using aluminum components.

Because aluminum lends itself well to extrusion, this production method has great potential to reduce the cost of fabrication components from aluminum. However, the automobile industry has limited experience fabricating aluminum parts using alternative processes. The know-how necessary to work

${ }^{8}$ Further development of Canadian hydroelectric resources appears to face greater political opposition than in the past. 
with aluminum exists in other industries-for example, aluminum doors and architectural fittings-that do not have the same cost and performance requirements of the automotive industry.

Extrusion is fundamentally different from stamping or casting; using it, therefore, will require substantial investment in new component production capacity and retooling of existing capacity dedicated to stamping or casting. Once a stamping process has been replaced by an extrusion process, the cost of retooling to change from one extrusion design to another may be comparable to the cost of retooling to change stamping designs, but the initial investment in extrusion equipment will be substantial. Therefore it seems likely that the industry will prefer to continue using existing metal forming methods, and that it will switch to new ones only if the methods are expected to produce large improvements in cost or performance, or only if new capacity is being developed. Substitution is likely to be easier in niche markets, such as sports cars, than in high-volume markets, such as family sedans. Purchasers of niche cars often are willing to pay higher costs for new technology or better performance. Production for a niche market allows automobile and component manufacturers to develop expertise without putting a larger market at risk from technical, design, or performance difficulties that might result from using a new material or component.

According to persons familiar with the aluminum industry, the automobile industry has in the past substituted aluminum for steel components in order to rapidly meet fuel economy or other targets, and then redesigned the model for the longer term to replace the aluminum components with steel. The return to steel apparently occurs because of the automobile industry's greater familiarity with steel and because of the greater price volatility for aluminum. Such a pattem of materials shifting is unlikely to induce the aluminum industry to make large investments in new capacity in anticipation of NGVs. Automobile manufacturers may need to sign long-term contracts for delivery of aluminum, or invest in their own aluminum production capacity as they historically did for steel, to reassure the aluminum industry that they are committed to the material's use.

\subsection{Vehicle Assembly}

The substitution of aluminum components for steel in automobiles requires the use of different procedures for joining components to each other. Joining methods are varied, depending upon the components to be joined, the performance requirements of the joints, and the characteristics of the materials that make up the components. Vehicle design changes, even those not involving new materials, can require changes in joining methods if the design affects the forces acting upon the joint or if greater strength is required. A shift to aluminum frame and body components probably would require a shift from welding to adhesives and other joining methods, with consequent replacement of capital equipment. In addition, it will take time for the industry to become familiar with new joining techniques for aluminum and to adapt them to an automotive environment. However, although research continues into new methods for joining aluminum, there appears to be a wide enough range of methods available to support NGV production using aluminum frames and bodies. In many instances these will require little change from those used for assembling steel components. This is especially true if the NGV uses aluminum alloys that are being used in manufacturing now. Product design engineers prefer to have extensive experience with a material-a decade or more-before using it in high production volumes for structural applications such as automobile bodies. This suggests that the alloys that will be used in the early stages of the PNGV must now be in fairly common use in order to provide the necessary experience.

\subsection{Vehicle Use and Repair}

Two issues arise at this life-cycle stage. One is whether the vehicle costs more or less to maintain, use, and repair. Without specific vehicle designs for NGVs, it is difficult to answer this question. It appears that aluminum can be used with equivalent or less susceptibility to corrosion than steel, and it appears that methods for repairing vehicle damage, particularly accident damage, have been developed and 
could be introduced to work with aluminum instead of steel. However, changes in vehicle design, especially those that involve consolidation of several simple components into one complex one, could make damage repair more expensive by requiring replacement of larger components after an accident, and this could increase the cost of automobile insurance and thus the cost of owning and operating the vehicle. The net effect of increased aluminum use on use and repair costs will not be known until NGVs are produced.

The second issue is the need to develop and maintain two sets of vehicle repair and maintenance technology during the transition to NGVs. Techniques for repairing a dent in sheet aluminum are not necessarily the same as those for sheet steel, and the use of the: wrong methods can increase rather than repair damage. Repair techniques exist now and no doubt will be improved as NGVs penetrate the marketplace. However, during the transition to NGVs, it will be necessary to train mechanics and body shops to repair the new materials. During the transition there will be two sets of repair equipment. Independent of the issues raised in the paragraph above, this duplication and the need for new training probably will increase costs of repair in the early years of the transition until the aluminum repair market is large enough to support independent repair facilities. 


\section{MAGNESIUM}

\subsection{Findings}

The findings of this chapter are summarized in Table 4-1. Because magnesium can be recovered from seawater or brines, or from minerals such as magnesite, dolomite, or olivine, the supply of this material is virtually limitless. Current production capacity (500 annual metric tons) would have to be doubled or tripled, requiring an investment of $\$ 13.1$ billion, to meet NGV demand in 2030 (assuming no recycling). New production capacity would be built outside the U.S., in part because magnesium production is electricity-intensive. Magnesium production for NGVs in 2030 would use six times the energy required for baseline vehicles-requiring 78-155 GWh of generation by 2030 to produce magnesium for NGVs.

As there is nothing to indicate differently, this analysis concludes that NGV magnesium components will likely be fabricated as they are now, by diecast. The casting processes for magnesium differ from those for steel, but these processes should not be technically difficult for the automobile industry or its workforce to adopt. The adoption of magnesium likely will occur on a part-by-part substitution basis, with little or no parts redesign.

The use of magnesium as assumed in the NGV scenarios may require new equipment and some change in vehicle maintenance and repair skills. Repair costs may rise some as NGVs are being phased in and repair shops acquire new equipment and training for technicians.

\subsection{Baseline and NGV Demand: Material Input}

Approximately 14 thousand metric tons of magnesium were used for diecasting in 1994, virtually all of it for automobile components (Metals Information Analysis Center 1996). The amount is projected to increase rapidly through the mid to late 1990s (Minerals Yearbook 1994). Thus, the amount of magnesium to be used in the base vehicle is projected to be much greater than at present. However, because industry projections are not available, this analysis uses the current five pounds of magnesium per car (the current per vehicle content) as the baseline. NGV demand for magnesium is projected to be two thousand metric tons in 2007 and between 597 and 1,195 thousand metric tons in 2030. Because magnesium can be extracted from sea water or brines and magnesium compounds such as dolomite, magnesite, or olivine, the supply is virtually limitless. Therefore availability of the resource will not affect cost.

\subsection{Extraction/Production}

Available information treats the magnesium extraction and production processes jointly; this anlaysis employs the same approach. Magnesium can be produced electrolytically from sea water or brines, or it can be produced thermally from magnesium compounds such as dolomite or olivine.

Approximately $75 \%$ of the US production capacity is electrolytic, the remainder uses dolomite (Minerals Yearbook 1994). World production capacity is split similarly.

Present world production capacity for magnesium was estimated at 500 thousand annual metric tons in 1994. Primary production was only 267 thousand metric tons, a $25 \%$ decrease from 354 thousand metric tons in 1990 (Minerals Yearbook 1994). Despite excess production capacity and virtually limitless natural resources from which it can be extracted, magnesium is considered to be in short supply. This situation is due, in part, to anti-dumping regulations targeted at members of the former Soviet Union that have idled some existing capacity (Minerals Yearbook 1994). World supplies are projected to remain tight through the late 1990s until new planned production capacity begins production. 
Table 4-1. Issues associated with magnesium use in NGVs

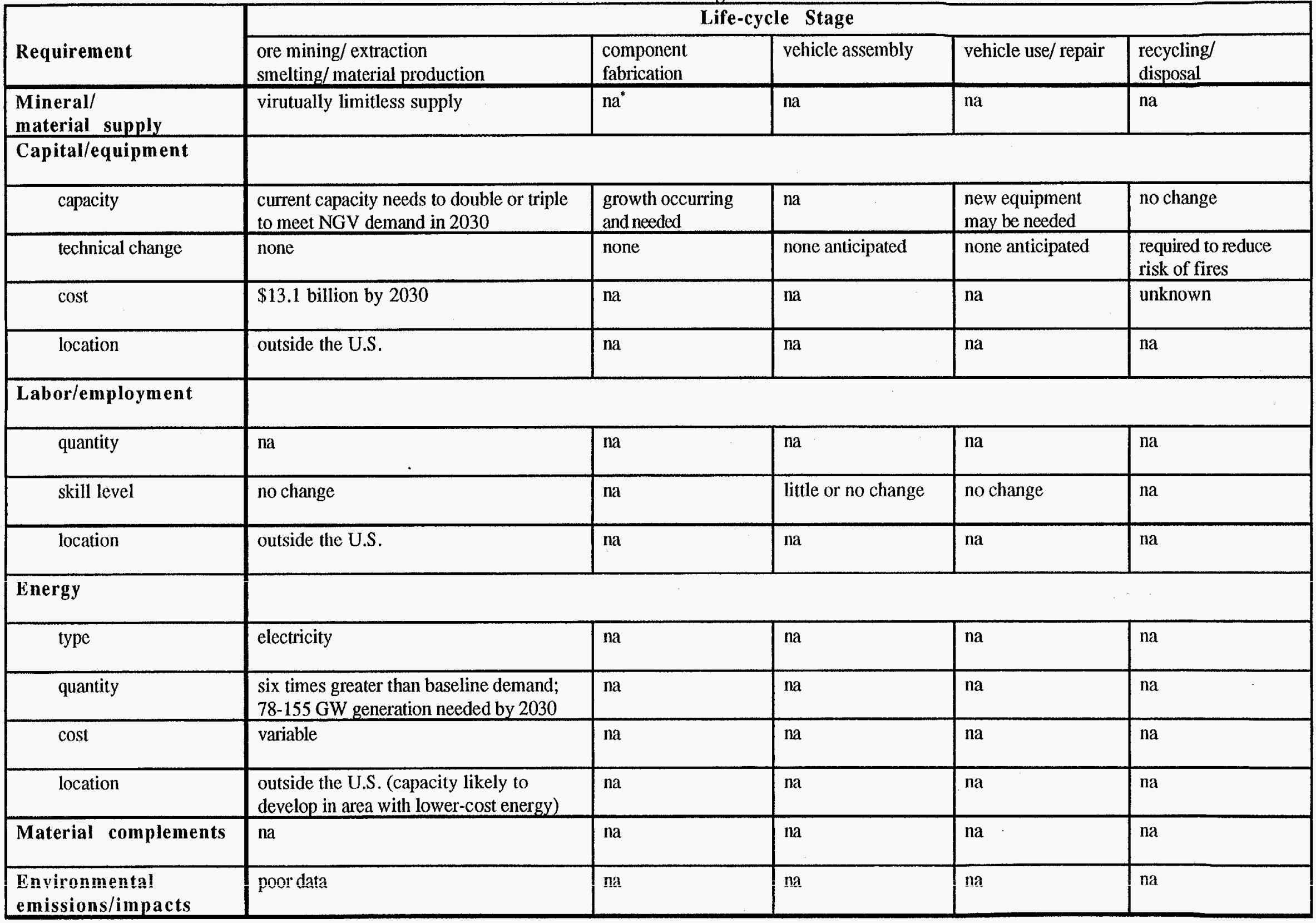

"The entry "na" means not applicable, or not addressed for lack of data or because it is beyond the scope of the report. 
NGV production in 2030 would require on the order of a doubling or tripling of current world production capacity-a 3.5-5.4\% annual increase over a 23-year period. (Table 4-2 summarizes production requirements to meet NGV demand for magnesium, by five year increments.) Also, it is not clear how much of the world's present production capacity will remain available at the start of NGV production. Retirement and dismantling of present excess production capacity could further increase the production growth rates required to supply magnesium for NGVs; however, this capacity retirement is not likely to occur if producers have reasonable expectations that demand will increase. Increased consumption in the base vehicle and in nonautomotive uses would reduce these growth rates somewhat. Nevertheless, the required increases in production would still be very large even if the industry had been increasing production and capacity during the past several years. The location of new production capacity may depend on energy costs, as magnesium production is energy- or electricity-intensive.

\begin{tabular}{|l|l|l|l|l|l|l|}
\hline \multicolumn{6}{|c|}{ Table 4-2. Increases in magnesium production and associated requirements to meet NGV } \\
demand \\
\hline Requirements & 2007 & 2010 & 2015 & 2020 & 2025 & 2030 \\
\hline $\begin{array}{c}\text { magnesium and } \\
\text { production } \\
\text { capacity (tmt) }\end{array}$ & $0-2$ & $0-17$ & $30-158$ & $87-530$ & $244-1,002^{\mathrm{b}}$ & $597-1,195^{\mathrm{b}}$ \\
\hline $\begin{array}{c}\text { investment in } \\
\text { production } \\
\text { capacity (\$M) }\end{array}$ & $0-22$ & $0-187$ & $330-1,738$ & $957-5,830$ & $2,684-11,022^{\mathrm{b}}$ & $6,567-13,145^{\mathrm{b}}$ \\
\hline electricity (GWh/yr) & $0-0$ & $0-0$ & $0-17$ & $9-69$ & $35-129$ & $78-155$ \\
\hline
\end{tabular}

a thousand metric tons

$b$ assumes no recycling. Recycling of NGVs could become a significant source of supply in the early $2020 \mathrm{~s}$ in the high penetration scenario, thereby reducing the amount of new smelting capacity required.

No technical changes in production, and therefore no change in the skills of the production labor force, would be required to meet NGV demand for magnesium.

Recent production capacity investments show a range of costs from $\$ 7,186$ to $\$ 14,032$ per metric ton annual capacity (Minerals Yearbook 1994, Wall Street Journal 1996), averaging $\$ 11,000$ of capital investment per annual metric ton. No information was available on variable costs. Assuming an investment of $\$ 11,000$ /annual metric ton, and magnesium requirements as listed in Table $4-2$, the PNGV would require an investment of $\$ 22$ million in magnesium production capacity in 2007 , but this would increase to a total of $\$ 13.1$ billion by 2030 .

On a per weight basis, magnesium requires more energy to produce than aluminum. Electricity consumption is estimated to be $130 \mathrm{kWh} / \mathrm{kg}$ of magnesium produced (Lee et al. 1991), about 18 times more intensive than steel. For any given application, however, magnesium would be only six times more energy intensive than steel since only one-third as much magnesium (by weight) will be required. About $78-155 \mathrm{GWh}$ of generation would be required by 2030 to produce magnesium for NGVs. The large energy requirements suggest that most magnesium production capacity will be developed outside the U.S. and other regions with high energy costs. Data on emissions from secondary magnesium smelting are very poor. Emissions include hydrochloric acid from reaction of the flux with moisture in the air, particulate magnesium oxide emitted during smelting, and some nitrogen oxides and carbon monoxide. 


\subsection{Component Fabrication}

Of the three primary methods of producing components from metal-diecasting, stamping, and extrusion-only diecasting is used extensively for producing magnesium components. No change in fabrication methods is expected in the NGV scenarios. Magnesium components most likely will be substituted for steel ones on a part-by-part basis, although some component redesign may occur to reduce the number of parts and hence assembly costs.

Firms are presently investing in new magnesium diecasting facilities, in anticipation that automakers will increase their demand for magnesium components (Minerals Yearbook 1994). The information on the capacity and cost of these facilities is insufficient for projecting overall investment requirements to meet $\mathrm{NGV}$ needs.

As with aluminum components which replace steel ones on a part-by-part basis, magnesium components can be replaced by steel ones again if magnesium price increases warrant the change. Such ease of reversing choice of materials is unlikely to induce the magnesium industry to make large investments in new capacity in anticipation of NGVs. Automobile manufacturers may need to sign long-term contracts for delivery of magnesium, or invest in their own magnesium production capacity, as they did for steel historically, to reassure the magnesium industry that they are committed to the material's use.

\subsection{Vehicle Assembly}

The processes for joining magnesium components can differ from those for joining steel ones, although this depends on the component and vehicle designs. In the applications envisioned for magnesium in the NGV scenarios, these processes should not require substantially greater skill levels to use but may require the use of new equipment. The NGV scenarios assume that magnesium use would be limited mostly to diecast components in the power train. These limited applications would not introduce substantial need for welding and other non-mechanical methods for joining magnesium to other components. Joining by use of lugs, bolts, and similar mechanical fasteners is likely to require less adaptation to accommodate magnesium than would be required by welding and adhesives.

\subsection{Vehicle Use and Repair}

The limited application of magnesium to die-cast, out-of-view components in the NGV scenarios is unlikely to create the same potential for increased vehicle repair costs that may arise with aluminum in body panels and other visible components. Methods for repairing magnesium components exist now and will be improved as NGVs penetrate the marketplace. There is little likelihood of design changes that result in larger, more complicated magnesium components that are more expensive to replace or repair. However, the net effect of increased magnesium use on vehicle use and repair costs will not be known until NGVs are produced.

The second issue is the need to develop and maintain two sets of vehicle repair and maintenance technologies during the transition to NGVs. During the transition to NGVs, it will be necessary to train mechanics and body-shop staff to repair the new materials. Additional repair equipment and new or re-trained repair workers will be necessary and will result in increased costs of repair in the early years of the transition until the magnesium repair market is large enough to support independent repair facilities. These requirements may have some impact in the early years of transition, but over the long term as new facilities are opened or old ones converted to magnesium repair, the NGVs should have little effect on auto repair industry. The effect would be much larger if magnesium were to be used in body panels and similar components that are highly visible and that require high level of skill to repair. 


\section{POLYMER COMPOSITES}

\subsection{Findings}

The findings of this chapter are summarized in Table 5-1. Polymer composites are fabricated material systems made of carbon or glass fibers imbedded in a plastic resin matrix. A $12 \%$ increase above current domestic production of acronytrile, the raw material for a class of carbon fibers likely to be used in carbon-fiber-based composites, is needed by 2015 to meet NGV demand. U.S. production capacity of silica - the raw material for glass fibers-should accommodate NGV demand readily. Matrix materials for composites are petroleum or natural gas based; therefore, their cost is driven by the supply of these feedstocks.

Textile acrylic fibers (obtained from acrylonitrile) used in the carbon fiber production are known as precursor fibers. We estimate that about 306,000 metric tons/year of low cost precursor fibers will be necessary annually for NGVs by the year 2015, requiring an increase of more than 1.5 times the existing U.S. production capacity. The growth in the demand for carbon fibers due to NGVs is likely to stimulate large producers of low cost precursor fibers, particularly once manufacturers feel confident about strong, persistent demand in the marketplace. However, new facilities could be located outside the United States (where labor is cheaper) to achieve lower production costs.

The carbon fiber industry, which converts precursor fibers for application, is a small, embryonic industry. Although worldwide, commercial-grade, carbon fiber production capacity is expected to more than double before 1998 , bringing worldwide production capacity to 5800 metric tons/year, this capacity represents only $4 \%$ of NGVs' total requirement of 139,000 metric tons in 2015 . Carbon fiber manufacturing is capital intensive. A projected investment level of $\$ 4,600 \mathrm{M}$ will be needed to meet NGV demand in the year 2015. The carbon fiber production technology is highly automated and does not require high skill levels. About $3.8 \mathrm{Twh} / \mathrm{year}$ energy would be consumed to produce carbon fibers required for NGVs by the year 2015.

The use of high temperature and reactive toxic chemical products in carbon fiber manufacturing poses significant environmental concerns, resulting from generation of highly toxic volatiles, such as cyanic acid, and huge amounts of carbon dioxide. Volatile organic emissions also result from the production of precursor fibers.

The global glass industry operates at near full capacity due to steady growth in demand. Increases in demand before the year 2000 are expected to exceed capacity expansion during the same time period. Thus, new investment of $\$ 335 \mathrm{M}$ would be needed to build production capacity required by NGVs by 2015 . Total investments necessary would increase from $\$ 335 \mathrm{M}$ to $\$ 1,840 \mathrm{M}$ if $\mathrm{S}-2$ glass fibers, rather than E-glass fibers, are necessary for NGVs. Initial capacity expansion will occur at existing production facilities both within and outside the U.S. It is anticipated that the greenfield facilities being planned will be built only when strong demand is assured from the automobile industry. Although capital intensive, the glass fiber industry does not require highly skilled labor.

We estimate that about 2.8 trillion Btus of energy will be needed to meet glass fiber demand for NGVs in 2015. Producing the carbon fibers required by NGVs would require 3 times more energy than producing glass fibers required by NGVs. The installation of scrubbers at manufacturing plants and decreasing waste streams by recycling have reduced the environmental impacts of the plants. We estimate that about 172,700 metric tons of carbon dioxide and 110 metric tons of particulate matter will be emitted due to glass fiber production for NGVs in 2015.

Most of the polymer composite applications being considered for NGVs, currently are defined as advanced polymer composites (APC) which currently account for less than $1 \%$ of the total polymer 
Table 5-1. Issues associated with polymer composite use in NGVs

\begin{tabular}{|c|c|c|c|c|c|c|}
\hline \multirow[b]{2}{*}{ Requirement } & \multicolumn{6}{|c|}{ Life-cycle Stage } \\
\hline & $\begin{array}{l}\text { ore mining/ } \\
\text { extraction }\end{array}$ & $\begin{array}{l}\text { Smelting/ } \\
\text { material } \\
\text { production }\end{array}$ & $\begin{array}{l}\text { component } \\
\text { fabrication }\end{array}$ & vehicle assembly & $\begin{array}{l}\text { vehicle use/ } \\
\text { repair }\end{array}$ & $\begin{array}{l}\text { recycling/ } \\
\text { disposal }\end{array}$ \\
\hline $\begin{array}{l}\text { Mineral/ } \\
\text { material supply }\end{array}$ & $\begin{array}{l}\text { ample silica for } \\
\text { glass fibers; } 12 \% \\
\text { increase in } \\
\text { acronytrile needed } \\
\text { for carbon fibers by } \\
2015 ; \text { matrix is gas } \\
\text { or petroleum based }\end{array}$ & $\mathrm{na}^{*}$ & na & na & na & na \\
\hline \multicolumn{7}{|l|}{ Capital/equipment } \\
\hline capacity & na & $\begin{array}{l}\text { existing carbon } \\
\text { fiber production } \\
\text { capacity is only } 4 \% \\
\text { of demand in } 2015\end{array}$ & $\begin{array}{l}\text { production capacity } \\
\text { is only 4-5\% of } \\
2015 \text { NGV demand }\end{array}$ & $\begin{array}{l}\text { new joining } \\
\text { infrasturcture needed }\end{array}$ & $\begin{array}{l}\text { repair equipment } \\
\text { could differ }\end{array}$ & no change \\
\hline technical change & na & none & none & $\begin{array}{l}\text { new joining } \\
\text { methods applied to } \\
\text { fewer parts }\end{array}$ & na & no change \\
\hline $\operatorname{cost}$ & na & $\begin{array}{l}\$ 4,600 \text { million by } \\
2015 \text { for carbon, } \\
\$ 335 \text { million for } E- \\
\text { glass fibers or } \\
\$ 1,840 \text { million for } \\
\$-2 \text { glass }\end{array}$ & $\begin{array}{l}\$ 560 \text { million or } \\
\$ 420 \text { million for } \\
\text { glass- and carbon- } \\
\text { based composite } \\
\text { manufacturing } \\
\text { capacity by } 2015 \\
\end{array}$ & $\begin{array}{l}\text { investment expected } \\
\text { to be less than } \\
\text { required by baseline }\end{array}$ & na & no change \\
\hline location & na & na & na & na & na & na \\
\hline \multicolumn{7}{|l|}{ Labor/employment } \\
\hline quantity & na & $\begin{array}{l}\text { carbon fiber } \\
\text { industry highly } \\
\text { automated }\end{array}$ & na & na & na & na \\
\hline skill level & na & $\begin{array}{l}\text { neither glass nor } \\
\text { carbon-fiber } \\
\text { industry requires } \\
\text { high-skill level }\end{array}$ & na & na & na & na \\
\hline location & na & $\begin{array}{l}\text { growth likely both } \\
\text { in and outside of } \\
\text { the U.S. }\end{array}$ & na & na & na & na \\
\hline
\end{tabular}


Table 5-1. Issues associated with polymer composite use in NGVs (continued)

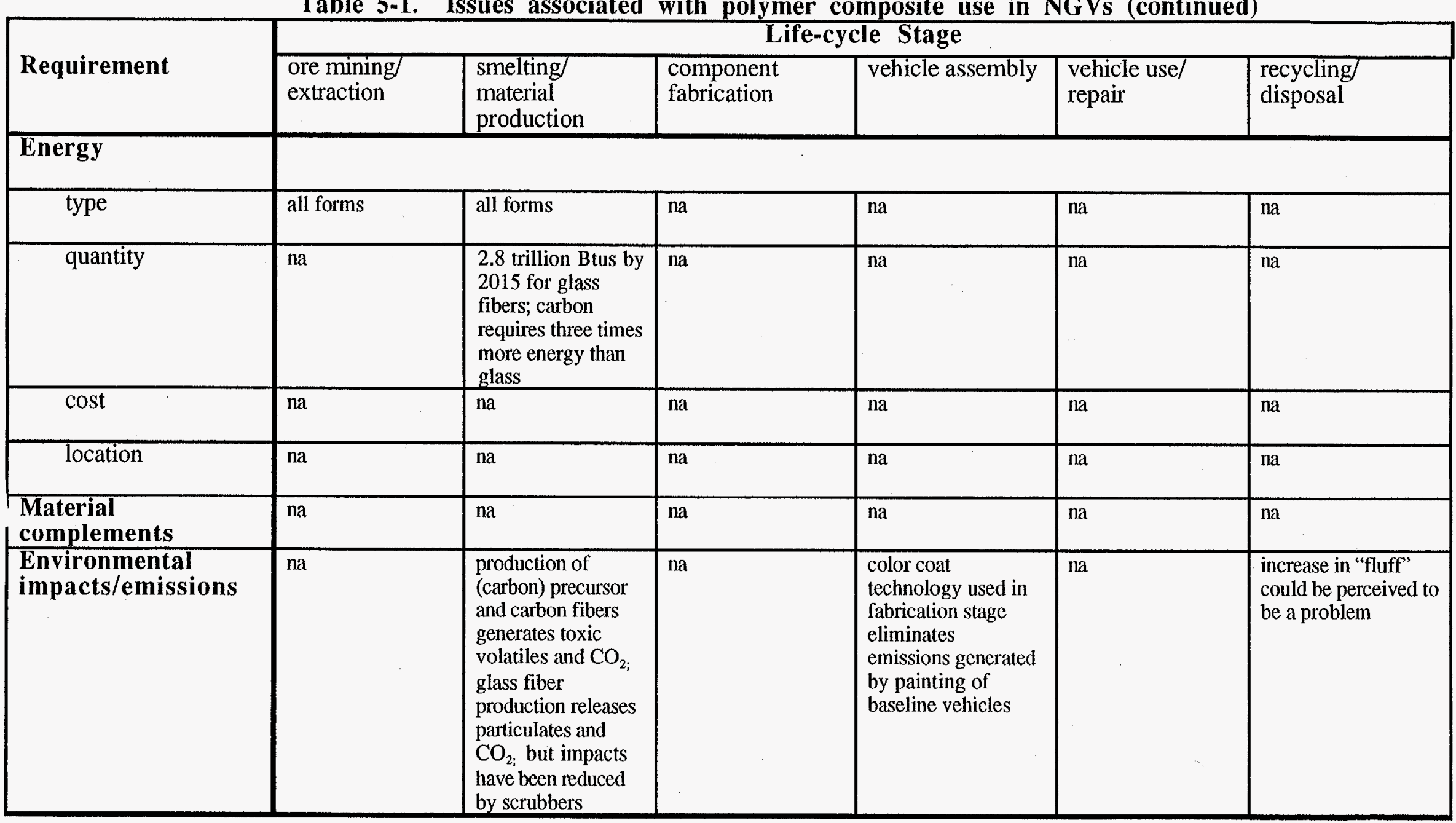

\footnotetext{
"The entry "na" means not applicable, or not addressed for lack of data or because it is beyond the scope of the report.
} 
composites market. Even with an anticipated doubling of production capacity before 2003, this would represent only 4-5\% of NGV demand in 2015. NGVs would require dramatic growth of the APC industry. By 2015 a capacity investment of $\$ 560 \mathrm{M}$ would be necessary for GRC, whereas $\$ 420 \mathrm{M}$ would be required for CRC. Also, composites fabrication technologies are more labor intensive than conventional steel sheet stamping.

Investments and labor required at the vehicle assembly stage for composite vehicles are anticipated to be lower than that for the conventional steel vehicles. However, a new joining infrastructure would be required, albeit for a smaller number of parts. During fabrication, composite parts could be painted using lay-in-the-mold color coat technologies, resulting in a significant reduction in emissions at the vehicle assembly stage.

The repair cost of composite vehicles is anticipated to be high due to parts consolidation. This could affect insurance, and thus, vehicle ownership costs.

\subsection{Ore Mining/Extraction}

Polymer composites are fabricated material systems made of carbon or glass fibers imbedded in a plastic resin matrix. Under the first two life-cycle stages of polymer composites, infrastructure issues are addressed at the level of its components, i.e., carbon or glass fibers and plastic.

Carbon fibers are petroleum-based materials that are derived either from a high-quality, rayon-like textile fiber known as polyacrylonitrile (PAN) or from a complex byproduct of coal-tar and petroleum processing called mesophase pitch. The former variety of carbon fibers, known as PANbased fibers, is more widely used because of its cost-effectiveness; the latter variety is known as pitchbased fibers. The chemical raw material used for the PAN-based carbon fibers is acrylonitrile-a monomer produced from propylene and used in large quantities by the textile fiber industry. The U.S. is a net exporter of propylene; hence, its availability for the production of acrylonitrile is not expected to be a matter of concern unless the a strong demand forecasted for acrylonitrile's other major derivative (i.e., polypropylene) causes a short term supply problem.

Acrylonitrile is considered to be a well established industrial chemical commodity, with a worldwide production capacity of 10 billion pounds in 1993. U.S. production of acrylonitrile totaled 2.46 billion pounds in 1993; worldwide production totaled 8.25 billion pounds (Delong 1994). The estimated 306 million lbs. of acrylonitrile required for NGVs by the year 2015 represents $12 \%$ of the current domestic production level.

Silicon and oxygen-the two most abundant elements in the earth's crust-combine to form silicon dioxide (commonly known as silica), the raw material base of glass fibers. Thus, silica's availability is not limited by mineral resources availability. The United States is a net exporter of silica, with an estimated production level of 28.2 million metric tons in 1995, accounting for $25 \%$ of total world production (ACSB 1996). U.S. plants operate at less-than-full capacity - a situation expected to continue in the long term. Other raw materials used in the glass fiber manufacturing are limestone, soda ash, and feldspar which are abundant.

Environmental concems regarding silica have resulted in major expenditures to bring plants into compliance with air emissions standards. The high cost of compliance has forced some silica companies to close grinding mills and packaging lines.

The polymer matrix material being considered for glass reinforced composites is polyurethane; for carbon reinforced composites it is epoxy. These materials are derived from either petroleum or natural gas feedstock, and, hence, their supply is driven primarily by petroleum and natural gas feedstock prices. Less energy is needed to extract the raw material (crude oil) for the composite 
matrix than is required to extract the metal ore required for baseline vehicles. Emissions from matrix material extraction should also be minimum.

\subsection{Material Production}

\subsubsection{Carbon fibers}

Textile acrylic fibers (obtained from acrylonitrile) used in the carbon fiber production are known as precursor fibers. About 2.2 units of precursor fiber produce 1 unit of carbon fiber. Precursor fiber production currently is small, and carbon fiber manufacturer's quality requirements are high; therefore, almost all carbon fiber manufacturers currently produce their own precursor fibers. The cost of precursor fiber is one of the key factors contributing to the higher cost of carbon fibers today. The limited worldwide capacity of low-cost, precursor fibers necessary for low-cost, high volume commercial grade carbon fibers is based primarily in Europe and Japan; only Monsanto and Cytec produce the fibers in the United States (Prescott 1996). Nevertheless, it is anticipated that availability of these precursor fibers will not be a problem once the carbon fiber manufacturers feel confident about strong demand in the marketplace.

Precursor fiber production capacity in the United States totals about 200,000 metric tons/year (Prescott 1996). We estimate that about 306,000 metric tons/year of low cost precursor fibers will be necessary annually for NGVs by the year 2015, requiring an increase of more than 1.5 times the existing U.S. production capacity. Depending on the type of production technology used, some of the existing textile acrylic fiber production capacity could be easily converted to produce precursor fibers of the quality needed for automotive applications. The growth in the demand for carbon fibers due to NGVs is likely to stimulate large producers of low cost precursor fibers, but new facilities could be located outside the United States (where labor is cheaper) to achieve lower production costs. At higher production volumes, it also is likely that integrated facilities-where precursor and carbon fiber are both produced-may be cost effective (DeLong 1994).

The carbon fiber industry is still a small volume, specialty business-not much beyond embryonic stage as an industry. To date, use of carbon fibers has been limited to aerospace and military applications that require premium grade fibers $(>\$ 20 / \mathrm{b}$ ). Each of the twelve manufacturers world wide operates on a small scale; total production is estimated to be 9,400 metric tons/year today. In comparison, this is only about $1 \%$ of the current glass fiber production level. Total current U.S. carbon fiber production is estimated to be around 3,800 metric tons/year (Prescott 1996a). ${ }^{9}$ Only three manufacturers-Akzo Nobel and Zoltek in the U.S., and R.K. Carbon in the United Kingdomhave production capacity for commercial grade carbon fibers which have potential for larger volume, lower cost applications. Akzo Nobel has more than $80 \%$ of the current total commercial grade carbon fiber production capacity of 2,800 metric tons/year.

Although worldwide, commercial-grade, carbon fiber production capacity is expected to more than double before 1998 , bringing worldwide production capacity to 5800 metric tons/year, this capacity represents only $4 \%$ of total requirements of 139,000 metric tons for NGVs in 2015. As the industry cautiously plans expansion-it was hurt badly in the early 90 s due to shrinking aerospace and defense markets-it may be difficult for some companies to justify the very heavy and accelerated investment schedule necessary to meet NGVs' tremendous demand.

Carbon fiber manufacturing is capital intensive for the following reasons: (1) uniform high temperature processing at greater than $1000^{\circ} \mathrm{C}$; (2) costly materials of construction; (3) difficult-tohandle, reactive, toxic chemical products, i.e., acrylonitrile and cyanides; (4) custom designed, oneof-a-kind equipment; and (5) inert atmosphere during processing (Delong 1994). Based on

\footnotetext{
${ }^{9}$ There are five U.S. manufacturers: Fortafil Fibers Division of the European manufacturer Akzo Nobel, Hercules, Amoco, Mitsubishi Rayon, and Zoltek.
} 
information on the BASF carbon fiber plant in Rock Hill, South Carolina, it is estimated that an investment of $\$ 30$ million (not including the investment required for precursor fiber) will be needed to add production capacity of 900 metric tons of fiber per year (Prescott 1995). Thus projected investment level of $\$ 4,600 \mathrm{M}$ will be needed to meet the demand for carbon fibers from NGVs by the year $2015 .^{10}$

Assuming that total energy required for carbon fiber production (including precursor fiber production) is about $12.5 \mathrm{kWh} / \mathrm{lb}$, where $10 \mathrm{kWh} / \mathrm{lb}$ is required during the carbon fiber production stage (Prescott 1996), we estimate that about $3.8 \mathrm{Twh} /$ year energy will be consumed to produce carbon fibers required for NGVs by the year 2015 .

The carbon fiber production technology is highly automated; production has to be on a continuous basis (i.e., 24 hours/day) for a cost-effective, efficient operation. Production is not labor intensive, and the skill level necessary for this kind of operation is not high.

The use of high temperature and reactive toxic chemical products in carbon fiber manufacturing poses significant environmental concerns. A huge amount of carbon dioxide [estimated to be 1.0$3.0 \mathrm{~kg} /$ metric ton of precursor fiber (Lee et al. 1991)] is generated when precursor fibers are incinerated to produce carbon fibers. Producing the carbon fibers required for NGVs in 2015 would generate 337 metric tons of carbon dioxide. Highly toxic volatiles such as cyanic acid $(\mathrm{HCN})$ are also generated during carbon fiber production. HCNs require extremely tight pollution control. There are also concerns for purifying acrylonitrile manufacturing water, which contains toxic and difficult to treat chemicals such as fumaronitrile. Air pollutants from the production of precursor fibers include emissions of acrylonitrile, solvents, additives, and other organics used in fiber processing. Nonmethane volatile organics emissions have been estimated to be $40 \mathrm{lbs}$ per $1000 \mathrm{lbs}$ of precursor fibers spun (EPA 1995).

\subsubsection{Glass fibers}

The glass fiber industry is both large and mature; the U.S. alone currently ships 1.4 million metric tons. Lower-grade E-glass fibers dominate production; however, NGVs would require significant amounts of high-performance S-glass fibers, which cost as much as five times more than E-glass fibers ( $\$ 1 / \mathrm{lb}$ for E-glass vs $\$ 5-7 / \mathrm{lb}$ for S-glass). Commercial grade $S$-glass fibers are produced by only one manufacturer (a U.S. company). Current shipments of glass fibers have to increase by $13 \%$ to meet NGV demand in 2015.

In contrast to the carbon fiber industry, the glass fiber industry is both large and mature. Because of its consistent quality, low cost, easy availability, and high processability, glass fiber is currently the most widely used fiber in structural composites, accounting for $99 \%$ of all fibers used in the composites industry. Two grades of glass fibers are available currently: E-glass and S-glass. Although most of the current automotive applications use inexpensive E-glass fibers, a low alkali borosilicate glass, NGVs could require significant amounts of high-performance S-glass fibers. The 1995 global glass fiber industry is estimated to be $\$ 4.3$ billion ( 2.3 million metric tons) in size, having major applications in construction (35\%), transportation $(20 \%)$, and electrical/electronic (15\%) industries (OFC 1996a). The automotive sector accounts for more than $80 \%$ of composites used by the transportation industry. The U.S. E-glass industry is well established; its three producers serve more than $60 \%$ of the global market. Owens Corning Fiberglass Corporation is the single worldwide producer of the commercial grade S-glass fiber, known as S-2 glass fiber. By the year 2015 , the current shipments of U.S. glass fiber of 1.4 million metric tons have to increase by $13 \%$ to meet the demand of NGVs.

\footnotetext{
${ }^{10}$ This estimate assumes all new capacity will be built for carbon fiber production for NGVs.
} 
The global glass industry continues to operate near full capacity due to steady growth in demand for composites. The industry is as competitive as ever, with producers struggling to fill orders and enduse manufacturers responding to the short supply by concentrating on premium products with the greatest consumer demand (Wuagneux 1995). Current industry forecasts suggest this situation may persist during the remainder of this decade, as shown in Figure 5-1. The composites market is forecasted to grow up to 5\% per year in North America and Western Europe during the next few years, and more than 10\% per year in Asia and Pacific countries (OFC 1996b). Total worldwide demand for glass fibers is forecasted to be around 3 million metric tons by $2000,0.7$ million metric tons more than 1995 production; however, only 0.5 million metric tons/year additional capacity is planned during that period (OFC 1996a). As growth in other markets-particularly construction and electronics-is forecasted to be strong, it is likely that there will be strong competition for glass fibers until the current supply situation improves. Thus, new investment to build production capacity is necessary to meet automobile industry demand.

The glass industry is capital intensive, and it requires sufficient loading of manufacturing plants to sustain profitability. Based on an investment of $\$ 200 \mathrm{M}$ for production capacity of 110,000 metric tons of E-glass fiber per year (Leach 1995), an investment of $\$ 335 \mathrm{M}$ would be needed by 2015 to meet the demand from NGVs. Investments would be substantially higher if S-2 glass fibers were used instead of E-glass fibers. An S-2 production plant of 4500 metric tons/year capacity is estimated to cost $\$ 45 \mathrm{M}$ (Leach 1995 ). Total investments necessary would increase from $\$ 335 \mathrm{M}$ to $\$ 1,840 \mathrm{M}$ if $\mathrm{S}-2$ glass fibers were necessary instead of E-glass fibers in NGVs. These new production facilities may be located within the United States as well as outside the United Sates due to lower production cost. For example, Owens Corning, which accounts for more than 50\% of the total capacity additions planned during this decade, is adding incremental fumace capacity to each of its facilities (in and outside of the U.S.) in addition to starting new furnaces, half of which would be outside the U.S. (e.g., Brazil, Korea, and India) (OFC 1996a). Due to the capital intensive nature of the glass industry, initial capacity expansion will occur at existing production facilities. It is anticipated that the greenfield facilities being planned will be built only when strong demand is assured from the automobile industry.

An increase in glass fiber production would require additional electricity supplies and associated infrastructure for generating and delivering power. Assuming that about 13.5 million Btus of energy is required to produce a metric ton of glass fiber, we estimate that about 2.8 trillion Btus of energy will be needed to meet its demand for NGVs in 2015 . Almost $80 \%$ of the energy requirement will be in the form of natural gas. Note that glass fiber manufacturing is at least six times less energy intensive than carbon fiber manufacturing (i.e., 13.5 million Btus/metric ton vs 85 million Btus/metric ton; however, twice as much glass fiber as carbon (by weight) would be required for a given application. The net result is that carbon fiber production required for NGVs would be 3 times more energy intensive than for glass. Glass fiber manufacturing is a highly technical, automated process. It is capital intensive, but does not require highly skilled labor.

The installation of scrubbers at glass fiber manufacturing plants has reduced concerns about the plants' emissions. An increasingly significant issue within the glass market is using recycled glass and decreasing manufacturing plants' waste streams. Owens Coming has successfully eliminated landfill waste at its Jackson, Tennessee facility by remelting glass waste (Wuagneux 1995).

Manufacturing scrap is also currently being recycled into loose-fill or, in the case of only a few companies, into new fiber glass products. We estimate that about 172,700 metric tons of carbon dioxide and 110 metric tons of particulate matter will be emitted due to glass fiber production for NGVs in 2015.

\subsubsection{Resin matrix material}

With resins occurring in a wide range of applications, U.S. resin sales have experienced rapid growth during the past several years. U.S. resin sales increased by $8.5 \%$ during 1994 , outpacing growth in 


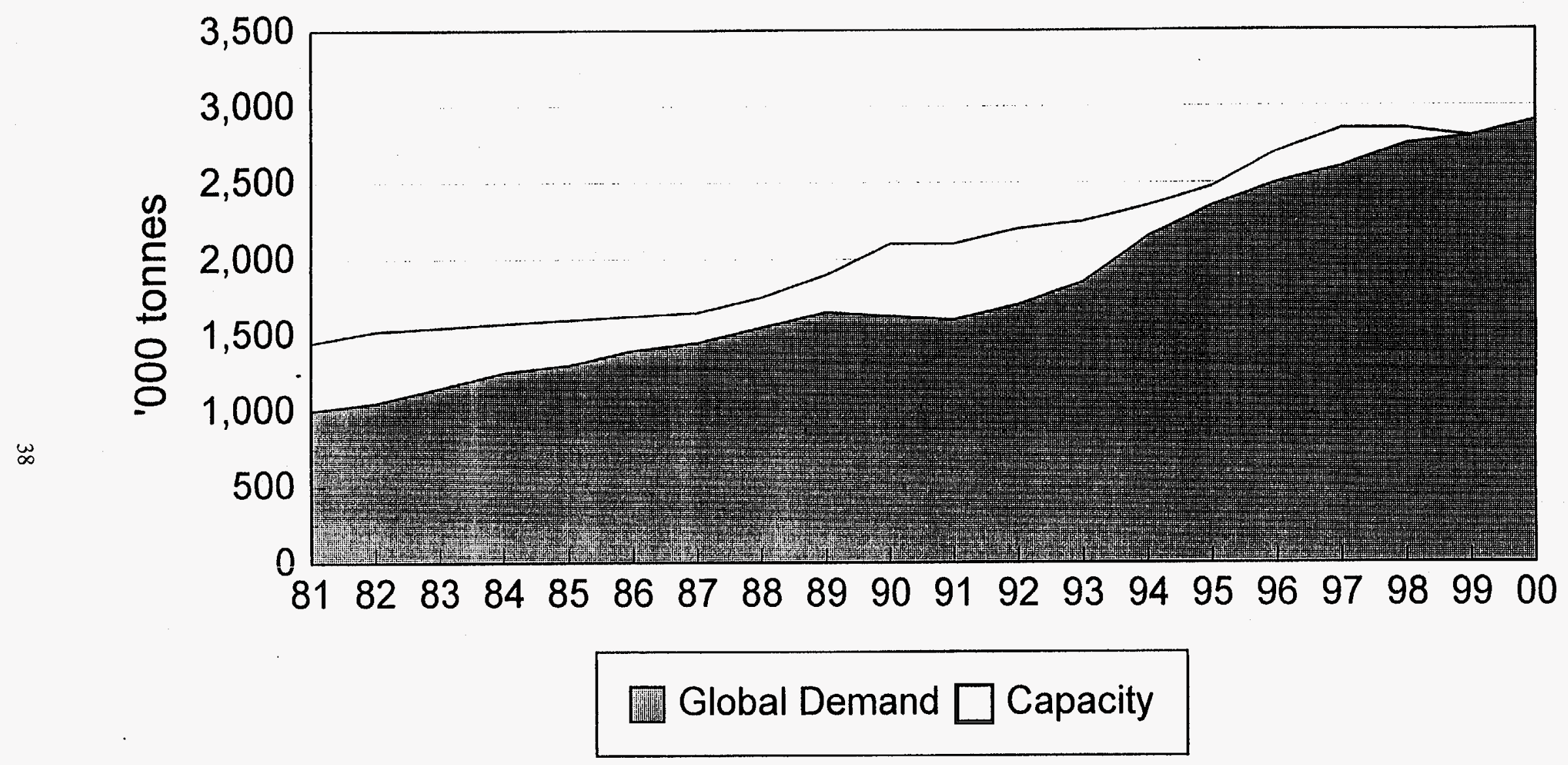

Figure 5-1. Glass fiber for composites industry - Global demand vs. capacity. 
the nation's economy. Total U.S. resin sales in 1994 were estimated at 35 million metric tons, of which 0.3 and 1.7 million metric tons came from epoxy and polyurethanes, respectively (Modem Plastics 1995). Eighteen percent of total U.S. polyurethane sales in 1994 were for transportation uses. The United States continues to be a net exporter in resin markets.

NGV demand for resin matrix materials is estimated to be 139,000 metric tons of epoxy and 184,000 metric tons of polyurethanes for the carbon-reinforced and glass-reinforced composites, respectively, by the year 2015. Total U.S. sales of epoxy and polyurethanes thus need to increase at an annual rate of $1.9 \%$ and $0.5 \%$, respectively to meet the demand from NGVs alone. The processing capacity for most resins is adequate-it is estimated that the utilization rate for most resin manufacturing capacity is about $80 \%$ (Miesel 1995). Globalization of world resin supply seems likely to increase, with future additions to world resin capacity increasingly being made overseas (e.g., China, Kuwait) to take advantage of availability of feedstocks and lower production costs.

Resin production includes the production of many precursors, which basically are produced from petrochemicals derived from crude oil through cracking. Assuming a total energy requirement of 96 million Btus per metric ton of epoxy production (Gaines and Shen 1980), we estimate that 15 trillion Btus will be used for the production of epoxy necessary to meet the projected CRC demand in 2015. For GRC, 19 trillion Btus of energy will be required (assuming 93 million Btus per metric ton of polyurethane production (Farissey (1991)) for the production of polyurethanes in 2015. Lee et al. (1991) estimate that on a per pound basis producing carbon fiber composites requires about $60 \%$ more energy than producing steel. Since the CRC required for a given application weighs about $60 \%$ less than the steel required for that same application, the total energy requirement will remain the same as the baseline.

Environmental concerns during resin production stem mainly from wash water effluent. The wash water impact is measured by total oxidizable carbon demand (TOC) which measures the carbon containing components in the effluent. TOC for epoxy resin used for CRC is in the range of 8.8$17.6 \times 10^{3}$ (Lee et al. 1991). An additional challenge the polyurethane industry faces is finding safe, effective, low-cost replacements for chlorofluorocarbons.

\subsection{Component Fabrication}

The U.S. composites industry has experienced a dramatic uptum since the early 1990s. Shipments of composites in 1995 are estimated to have been 1.4 million metric tons, an increase of $34.5 \%$ since 1991. Annual growth has ranged from 4 to $15 \%$. The forecast is for the composites market to expand faster than the U.S. economy-an average of $3.6 \%$ per year through the year 2000 increasing from 1.4 million metric tons in 1995 to 1.7 million metric tons by the year 2000 (Grande 1995). The transportation sector accounts for the largest share of the U.S. composites industry- $31 \%$ of the market in 1995. The construction industry is the next largest market segment of the industry, accounting for $20 \%$ of the market. With the reduced growth rate of aerospace and military applications, transportation and construction sectors have been mainly responsible for the growth in the industry.

NGVs' demand for composites-278,000 metric tons of CRC or 364,000 metric tons of GRC by the year 2015-represents a 20 to $26 \%$ increase (for carbon or glass reinforced composites, respectively) above 1995 U.S. composite shipments. NGV demand alone would necessitate an annual average growth rate of 0.7 to $1 \%$ in U.S. composites industry shipments.

Most of the polymer composite applications being considered for NGVs, currently are defined as advanced polymer composites (APC). About 5,000 companies comprise the total U.S. composites industry, of which only about a few dozen are APC producers (McDermott 1996). The defense and aerospace industries have been the primary market for APC, and APC accounts for less than $1 \%$ of 
the total polymer composites market. In 1993, only 300 metric tons were used for automotive applications, mostly in Western Europe. It is forecast that by the year 2003, U.S. APC production will almost double to 14,100 metric tons (Eckert 1995). However, this production capacity represents only $4-5 \%$ of NGV demand in the year 2015. The APC industry needs dramatic growth to transform itself from its current niche market applications to low-cost, high-volume automotive applications.

Liquid composite molding (LCM) is considered one of the most favorable automotive parts fabrication technologies to meet cost/volume targets of PNGV. Investment and tooling costs for the fabrication of composites are considerably lower than steel, and less lead time is necessary to increase the production capacity. Although $32 \%$ of composites plants employ the LCM process, their capacity is very small and suited for custom applications. Hence, current capacity is not suited for automotive applications (McDermott 1996).

Assuming a $\$ 1,500 /$ metric ton capital investment for the fabrication of composite parts, we estimate that by 2015 a total investment of $\$ 560 \mathrm{M}$ will be necessary for GRC, whereas for CRC the required investment would be slightly lower, i.e., $\$ 420 \mathrm{M}$, because of lower quantity necessary. Most of the composite manufacturing facilities are currently located near the automobile manufacturing facilities. Locating fabrication facilities closer to the original equipment manufacturers will be important to allow the larger, consolidated auto parts to be transported safely and at a lower cost.

The cost effectiveness of composites results mainly from lower investment and tooling costs than would be required for steel. A cost comparison study of a generic fender using several competitive manufacturing technologies indicates that the composites fabrication technologies are in the range of 1.5-2.0 times more labor intensive than the conventional steel sheet stamping technology (Busch et al. 1987). The labor intensity will depend largely on the curing method used-less labor will be needed as the shift from chemical curing to electron beam curing takes place. Workers will have to be trained (or retrained) to meet the composites industry's demand for highly skilled labor. Since energy is not considered to be a significant factor in the total fabrication cost, minimal impacts are anticipated for energy requirements for composites fabrication.

\subsection{Vehicle Assembly}

A radical change in the design of composite-intensive vehicle (e.g., composite monocoque) from the conventional steel unibody design will require drastic changes in the vehicle assembly. A recent cost study on the life cycle cost comparison of different body-in-white material systems indicates that the low-piece count composite monocoque has the lowest assembly cost over all production volumes, estimated to be about $25 \%$ lower than the steel autobody at a production volume of 250,000 vehicles (Dieffenbach and Mascarin 1993). Investments and labor required at the vehicle assembly stage for composite vehicles are anticipated to be lower than that for the conventional steel vehicles.

Structural adhesive bonding and hybrid joining (bonding with mechanical fastening) have been identified as appropriate methods for manufacturing composite intensive vehicles. Currently, structural bonding is essentially non-existent in the automobile industry (except for windshields) and adhesive bonding is limited to the aerospace industry-thereby requiring the development of the complete joining infrastructure for the automobile industry. A very low count of the composite parts due to parts consolidation means that the amount of joining material is inherently small. Composite joining techniques pose few environmental or health-and-safety concerns as long as they are carried out in a controlled environment. For baseline vehicles, painting is the major contributing factor to emissions at the vehicle assembly stage. During fabrication, composite parts could be painted using lay-in-the-mold color coat technologies. This would result in significant reduction in emissions at the vehicle assembly stage. No quantitative estimates of the reduced emissions are currently available in the literature. 


\subsection{Vehicle Use/Repair}

The repair cost of composite vehicles is anticipated to be high due to parts consolidation. In some instances, the damaged section will be patched rather than replaced. The skills required for repair will be those of the boat builder than of the sheet metal worker. Currently there exists no infrastructure for repair, and the infrastructure needed will be completely different, at a lower level of investment but higher labor intensity compared to what exists today. Insurance cost of composite vehicles will be higher if they are perceived to be less safe and more expensive to repair. 



\section{ULTRA LIGHT STEEL AUTOBODY}

\subsection{Findings}

The findings of this chapter are summarized in Table 6-1. Annual demand for iron ore to produce the steel for NGVS would be 2,945 thousand metric tons by the year 2030 , increasing current consumption of iron ore by $3.4 \%$ and domestic production by $4.3 \%$. This increased demand could be met by domestic production if new production technologies can overcome the problem of declining quality of domestic ore grades. Insignificant increases in employment and energy use would result from the production of iron ore for NGVs.

High strength steels are characterized by their higher yield strengths than those of plain carbon structural steels, but still are considered plain carbon steels. The increase in carbon steel production necessary to meet the demand for high strength steel by NGVs-1,817 thousand metric tons. of high strength steel or $13 \%$ of current consumption by the automotive sector and $2 \%$ of current domestic production-is insignificant compared to both the current domestic production level and to recent growth in production. Increased demand could result in an employment increase of $2.5 \%$ in the steel industry; however, this effect is minimal and will likely be unrealized because productivity increases likely will continue. Energy required to produce the steel for NGVs represents a $2 \%$ increase in the energy requirements for current shipments of 98 million metric tons of steel mill products. Carbon dioxide emissions resulting from production of current steel shipments would increase by $2 \%$, while particulate emissions would increase by $5 \%$.

Fabrication technologies well developed in other industries would be adapted for automotive applications to produce the ULSAB. Each of the three fabrication methods under consideration would require would require production capacity building. The ULSAB design would cost less to manufacture than the baseline design, thus requiring less investments and operating costs (Johnsen 1995). It is anticipated that the ULSAB automobile assembly line will be more automated and faster than today's line, because fewer parts will require assembly and faster joining methods will be used. The radical change in vehicle design would rquire a new assembly method. Large capital investments will be required, but labor requirements will be reduced. Minimal changes in vehicle use and repair are expected.

\subsection{NGV and Baseline Demand: Material Input}

NGV demand for additional high strength steel is estimated to be 1,817 thousand metric tons by the year 2030. Assuming that 1.6 metric tons of iron ore is required to produce a metric ton of pig iron, 0.83 metric ton of pig iron per metric ton of raw steel, and 1.22 metric tons of raw steel per metric ton of steel sheet, annual NGV demand for iron ore would be 2,945 thousand metric tons by the year 2030. U.S. consumption of iron ore in 1995 is estimated to have been 86 million metric tons (USGS 1996c); therefore, NGVs would increase current consumption by $3.4 \%$.

At present consumption rates, known world iron reserves are sufficient to meet world demand well beyond the 21 st century. Domestic reserves are lower grade ore typically not suited to automotive applications; however, new production technologies may overcome this problem. Otherwise, NGV demand will be met by the imported semifinished steel.

\subsection{Mining/Ore Extraction}

U.S. iron ore production and shipments have increased proportional to crude steel production since the early 1990s. U.S. production of iron ore-68.2 million metric tons in 1995 - did not meet the demand of the steel industry because of the country's declining ore grades, the inland location of its 
Table 6-1. Issues associated with ULSAB use in NGVs

\begin{tabular}{|c|c|c|c|c|c|c|}
\hline \multirow[b]{2}{*}{ Requirement } & \multicolumn{6}{|c|}{ Life-cycle Stage } \\
\hline & $\begin{array}{l}\text { ore mining/ } \\
\text { extraction }\end{array}$ & $\begin{array}{l}\text { smelting/ } \\
\text { material } \\
\text { production }\end{array}$ & $\begin{array}{l}\text { component } \\
\text { fabrication }\end{array}$ & vehicle assembly & $\begin{array}{l}\text { vehicle use/ } \\
\text { repair }\end{array}$ & $\begin{array}{l}\text { recycling/ } \\
\text { disposal }\end{array}$ \\
\hline $\begin{array}{l}\text { Mineral/ } \\
\text { material supply }\end{array}$ & $\begin{array}{l}\text { NGVs to increase } \\
\text { U.S. consumption } \\
\text { of iron ore by } 3.4 \%\end{array}$ & $\begin{array}{l}2 \% \text { increase in } \\
\text { domestic } \\
\text { production would } \\
\text { meet annual NGV } \\
\text { demand in } 2030 \\
\end{array}$ & $\mathrm{na}^{*}$ & na & na & na \\
\hline \multicolumn{7}{|l|}{ Capital/equipment } \\
\hline capacity & $\begin{array}{l}4.3 \% \text { increase in } \\
\text { domestic } \\
\text { production required }\end{array}$ & $\begin{array}{l}\text { required capacity } \\
\text { available }\end{array}$ & $\begin{array}{l}\text { each of three new } \\
\text { technologies under } \\
\text { consideration would } \\
\text { require new capacity }\end{array}$ & $\begin{array}{l}\text { highly automated } \\
\text { assembly line using } \\
\text { new welding } \\
\text { methods needed }\end{array}$ & $\begin{array}{l}\text { repair capacity for } \\
\text { new joining } \\
\text { techniques needed }\end{array}$ & no change \\
\hline technical change & $\begin{array}{l}\text { new production } \\
\text { technologies could } \\
\text { allow use of lower- } \\
\text { grade U.S. ore }\end{array}$ & none & $\begin{array}{l}\text { techniques used in } \\
\text { other applications to } \\
\text { be adapted for } \\
\text { automotive } \\
\text { applications. }\end{array}$ & $\begin{array}{l}\text { new welding } \\
\text { techniques for } \\
\text { joining }\end{array}$ & $\begin{array}{l}\text { no significant } \\
\text { change }\end{array}$ & no change \\
\hline cost & na & na & na & na & na & no change \\
\hline location & no change & na & na & na & na & no change \\
\hline \multicolumn{7}{|l|}{ Labor/employment } \\
\hline quantity & $\begin{array}{l}\text { insignificant } \\
\text { increase }\end{array}$ & $\begin{array}{l}\text { potential for slight } \\
\text { increase likely to } \\
\text { be offset by } \\
\text { increases in } \\
\text { productivity }\end{array}$ & $\begin{array}{l}\text { likely to be less } \\
\text { than for baseline }\end{array}$ & $\begin{array}{l}\text { automation and } \\
\text { fewer parts would } \\
\text { reduce labor } \\
\text { requirements }\end{array}$ & $\begin{array}{l}\text { no significant } \\
\text { change }\end{array}$ & no change \\
\hline skill level & no change & no change & no change & no change & $\begin{array}{l}\text { no significant } \\
\text { change }\end{array}$ & no change \\
\hline location & no change & no change & na & na & na & no change \\
\hline
\end{tabular}

\footnotetext{
* The entry "na" means not applicable, or not addressed for lack of data or because it is beyond the scope of the report.
} 
Table 6-1. Issues associated with ULSAB use in NGVs (continued)

\begin{tabular}{|c|c|c|c|c|c|c|}
\hline \multirow[b]{2}{*}{ Requirement } & \multicolumn{6}{|c|}{ Life-cycle Stage } \\
\hline & $\begin{array}{l}\text { ore mining/ } \\
\text { extraction }\end{array}$ & $\begin{array}{l}\text { smelting/ } \\
\text { material } \\
\text { production }\end{array}$ & $\begin{array}{l}\text { component } \\
\text { fabrication }\end{array}$ & vehicle assembly & $\begin{array}{l}\text { vehicle use/ } \\
\text { repair }\end{array}$ & $\begin{array}{l}\text { recycling } \\
\text { disposal }\end{array}$ \\
\hline \multicolumn{7}{|l|}{ Energy } \\
\hline type & all forms & all forms & na & na & na & no change \\
\hline quantity & $\begin{array}{l}\text { insignificant } \\
\text { increase of } \\
5 \text { trillion Btus } \\
\text { annually by } 2030 \\
\end{array}$ & $\begin{array}{l}\text { demand for } 26 \\
\text { trillion Btus-- } 2 \% \\
\text { above industry's } \\
\text { current requirement }\end{array}$ & na & $\begin{array}{l}\text { no significant } \\
\text { change }\end{array}$ & na & no change \\
\hline cost & na & na & na & na & na & no change \\
\hline location & na & na & na & na & na & no change \\
\hline $\begin{array}{l}\text { Material } \\
\text { complements }\end{array}$ & $\begin{array}{l}\text { abundant limestone } \\
\text { and dolomite }\end{array}$ & na & na & na & $\mathrm{ma}$ & na \\
\hline $\begin{array}{l}\text { Environmental } \\
\text { impacts/emissions }\end{array}$ & none significant & $\begin{array}{l}1.3 \text { million tons of } \\
\mathrm{CO}_{2} \text { and } 2,800 \\
\text { tons of particulate } \\
\text { matter (equal to } 2 \% \\
\text { and } 5 \% \text {, } \\
\text { respectively, of } \\
\text { industry's current } \\
\text { emissions) }\end{array}$ & na & na & $\overline{\text { na }}$ & na \\
\hline
\end{tabular}


mines, and high energy and labor costs. Consequently, U.S. imports of iron ore continue to rise; in 1995 the industry imported 18\% of the ore it consumed (USGS 1996d). Annual NGV demand of 2,945 thousand metric tons (by 2030) represents an increase of $4.3 \%$ (or about $0.1 \%$. per year) in current domestic production. The increase in iron ore production necessary to meet NGV demand is so small that it could be met by domestic production. New cost-effective pig iron production processes such as direct-reduced iron (DRI) and the non-coke oven oriented COREX production technology are anticipated to help the domestic iron ore industry (USGS 1996d) overcome problems associated with declining ore grades.

The U.S. iron ore industry is mainly located in the Great Lakes region, i.e., Michigan and Minnesota. Smaller production occurs in California, New Mexico, South Dakota, Texas, and Utah. The industry currently employs 7,000 employees with an average production output of 3.5 metric tons of ore per hour (USGS 1996d). An increase of $4.3 \%$ in domestic iron ore production would result in an increase of about 300 employees by the year 2030. Thus the effect on the labor market would be insignificant. Assuming that 1.7 million Btus is required to prepare a metric ton of iron ore, annual NGV demand for iron ore would require 5 trillion Btus of energy annually by the year 2030-a fairly insignificant increase over a period of 25 years. No significant environmental concerns are associated with iron ore production.

Other materials required for iron ore making are limestone and dolomite, which are used for pelletization. These resources are abundant, and a small increase in demand will be met easily.

\subsection{Material Production}

This life cycle stage of high strength steel includes the production of pig iron from the iron ore and the conversion of the pig iron into steel mill products to be used in various applications. High strength steels are characterized by their higher yield strengths than those of plain carbon structural steels but still are considered plain carbon steels because of their low alloy contents (i.e., less than $0.25 \%$ ). U.S. production of carbon steel in 1994 is estimated to have been 89,320 thousand metric tons, about $89 \%$ of total steel production and $93 \%$ of the net total U.S. steel shipments of 94,939 thousand metric tons (USGS 1996b). It is estimated that about $15 \%$ of U.S. shipments of raw steel containing $\geq 95 \%$ of carbon steel go to the automobile sector (AMM 1995), resulting in a consumption of about 13,530 thousand metric tons of carbon steel in 1994. A demand increase of 1,817 thousand metric tons of high strength steel annually by the year 2030 due to NGVs will increase the current consumption of carbon steel in the automotive sector by about $13 \%$. If all the increased demand for carbon steel is met domestically, the U.S. production of carbon steel must increase by $2 \%$ by the year 2030 .

The increase in carbon steel production necessary to meet the demand for high strength steel by NGVs is insignificant compared to both the current domestic production level and to recent growth in production. Due to growth in applications of high-strength, low-alloy steels, domestic production of carbon steel has experienced an annual average growth of $0.8 \%$ since the early $1990 \mathrm{~s}$. This rate of growth is expected to continue in the future (USGS 1996b).

Currently, integrated steel producers with their unique processing capabilities (e.g., annealing) supply almost all the steel required by the automobile industry. The shift to high-strength steel can easily be adopted by integrated steel producers, although high-strength steel will result in a lower throughput. For minimills to produce the required quality of sheet steel for the automobile industry, additional investments would be necessary. Also, as some applications have shifted from using alloy steel to using high strength steel, alloy steel production has declined since the early 1990s (i.e., an annual average rate of $3.2 \%$ [USGS 1996a]). The ease of changing excess production capacity from alloy steel to high strength steel will further reduce the demand for additional production capacity 
and maintain the domestic industry's competitiveness for meeting NGVs' demand for high strength steel.

Total employment level in the steel industry (includes blast furnaces and steel mill products) in 1995 was 171,000, with three states-Indiana, Ohio, and Pennsylvania-accounting for almost 50\% of total employment (USGS 1996a). Assuming that integrated steel producers continue to supply steel for NGVs and current productivity of 419 metric tons of steel per employee for the integrated steel producers (Sawinski 1995), an increase in demand of 1,817 thousand metric tons of high strength steel will result in about 4,340 new jobs for the steel industry (an employment increase of $2.5 \%$ ). This effect on the labor market is minimal and will likely be unrealized because productivity increases likely will continue.

Higher demand for high strength steel due to NGVs will increase energy requirements. We estimate that 26 trillion Btus of energy will be required to produce the 1,817 thousand metric tons of high strength steel required by NGVs in the year 2030, assuming that 14.2 million Btus of energy are required per metric ton of steel in integrated steel making facilities. Most of the additional energy required will be in the form of fuel, i.e., coke. Additional energy requirements due to NGVs represent $2 \%$ of energy requirements for current shipments of 98 million metric tons of steel mill products (assuming the share between integrated and minimills for the current steel production is 60:40). Increasing production of high strength steel will increase emissions, the majority of which result from blast furnaces during pig iron making. It is estimated that the use of high strength steel in NGVs would result in total emissions of 1.43 million metric tons of carbon dioxide and

3.08 thousand metric tons of particulate matter by the year 2030 . These additional emissions correspond to $2 \%$ and $5 \%$ respectively, of the total emissions due to current steel mill shipments.

\subsection{Component Fabrication}

Fabrication of the ultra light steel auto body (ULSAB) using high strength steel would require several technologies used in other industries to be adapted for automotive applications. The technologies being considered for the ULSAB are tailor-welded blanking, hydroforming, and roll forming. They are considered to be proven, near-term, mass-production techniques, but no specific technical details are currently available on them for automotive applications. Of the three necessary fabrication technologies, hydroforming - a technology most used in Europe and relatively new in the United States - would require the most production capacity building. This technology is used selectively in ULSAB to replace sheet metal stampings. Hydroforming and roll forming production technologies, unlike tailor-welded blanking, require dedicated facilities to supply automobile parts. Therefore, PNGV-required increases in production capacity would be developed mostly by parts suppliers rather than by automobile manufacturers (particularly for the hydroforming technology due to unique processing requirements). No capital cost estimates are currently available for these technologies as adapted for the automobile industry. The United States' few, small-scale facilities are located mostly in Michigan.

It is anticipated that the ULSAB design would cost approximately $\$ 154$ less to manufacture than conventional designs (excluding vehicle assembly costs), thus requiring less investments and operating costs (Johnsen 1995). Since all three fabrication technologies are likely to reduce the total number of parts (hence the number of operations), labor requirements are likely to be less than that required for the conventional stamping technology. For example, hydroforming creates closed-box sections to improve structural performance, eliminate flanges, and reduce the total number of parts requiring welding (Blau 1996). Neither energy nor environmental estimates are currently available on any of the fabrication technologies. 


\subsection{Vehicle Assembly}

It is anticipated that the ULSAB automobile assembly line will be more automated and faster than today's line. ULSAB fabrication technologies will reduce the number of parts requiring assembly. Vehicle assembly will require more laser beam welding and adhesive weld bonding, methods faster than conventional spot welding. For example, laser welding is ten times faster than the best that can be done with robotic spot welding today. These new joining techniques, still in their developmental stages, are very expensive. Undoubtedly, their costs will decline once the techniques are fully developed. However, no capital investment estimates are currently available for them. A huge level of investments will be necessary to switch to the highly automated vehicle assembly line, but less labor hours will be needed for the vehicle assembly. Since energy requirements during vehicle assembly stage are small compared to that required during vehicle parts manufacturing stages, no significant increase in energy requirements is anticipated for the ULSAB design.

\subsection{Vehicle Use and Repair}

Because high strength steel is not drastically different from the steel used in automobiles today, this material substitution will cause the least change in vehicle use and repair. The existing infrastructure for repair can be utilized to a large extent. However, the infrastructure for new joining techniques such as laser beam welding will also need to be developed for vehicle repair. 


\section{NGVs and Automobile Recycling}

This section discusses the potential impacts of NGVs on the current automobile recycling infrastructure and the future viability of conventional automobile recycling industry.

\subsection{Findings}

- Under assumed conditions, NGVs will not be recycled until about 2018 and not in any significant numbers until 2020, which gives the recycle industry ample time to develop new recycle technologies and to modify their capital stock.

- The cost of capital represents only about $1 \%$ of the total cost of shredder operations. The undepreciated value of shredders and related equipment in the United States is about $\$ 950$ million. While large in absolute terms, the loss of a significant portion of this infrastructure would be small compared to other potential impacts of NGVs.

- The increased use of aluminum poses potentially serious technical problems-e.g., incompatibility of cast and wrought aluminum, incompatibility of different alloys, potential requirements for hand disassembly, contamination from paints and adhesives. If these potential problems do not affect per-unit costs and revenues, the adoption of aluminum intensive automobiles will be a financial boon to the shredder industry.

- According to industry sources, the increased use of magnesium would increase the risk of fires, requiring new technologies, and could decrease worker safety and drive up liability costs.

- The addition of composites will not affect the operation of automobile shredders or affect the operation of down-stream technologies. However, by decreasing the quantity of ferrous metals available for recovery and by increasing the amount of material for landfill, the economic viability of the current recycle infrastructure may be threatened.

\subsection{Background}

In the mid 1960 s, automobile shredders were introduced to reduce costs and to improve the quality of materials recovered. Capable of separating ferrous, non-ferrous, and other components, automobile shredder facilities have become the industry standard and are used to recycle more than $90 \%$ of scrap automobiles in the United States. Virtually all ferrous and non-ferrous metals are recycled (about 75 percent of the automobile's mass). The remaining 25 percent of the automobile's mass, e.g., plastics, rubber, fabrics, and dirt, is commonly referred to as automobile shredder residue (ASR) or "fluff" and is currently landfilled.

A shredder is capable of cutting and tearing a wide range of materials, such as tires, drums, appliances, as well as automobiles. Shredders are comprised of hammers connected to a rotor through axles called hammer pins. Automobiles are shredded when the hammers crush entering materials against an anvil. Following shredding, magnetic separators are used to collect ferrous metals. Eddy current separators are used to separate the remaining aluminum and other non-ferrous metallics, as well as some plastics.

Shredders range in size from $500 \mathrm{HP}$ to $6,000 \mathrm{HP}$. The typical output of a 4,000 HP super-heavyduty shredder is about 109 metric tons per hour, the equivalent of two cars per minute. As of 1995 , there were 211 shredder facilities in the United States. About 20-25 new shredders are added to 
existing capacity each year in the United States. Shredders have relatively long life spans of 1020 years or more. However, extensive maintenance is required due to wear of the contact parts.

Shredders are a mature technology, and technological change is expected to be incremental, not revolutionary. However, downstream processing technologies-especially separation technologies designed to sort specific non-ferrous metals and specific plastic resins-are still evolving.

Under assumed conditions, NGVs will not be recycled until about 2018 (NGVs penetrate the market in 2007 and are assumed to have lives of about 11 years-the current average). Significant numbers of NGVs will not be recycled until beyond the year 2020 . This gives the recycle industry ample time to adjust to changing material compositions.

\subsection{Economic Viability of the Current Recycle Industry}

In addition to reviewing relevant literature, several members of the industry (shredder manufacturers, down-stream equipment manufacturers, and shredder operators) were contacted to obtain information on the technical issues/obstacles that may be raised by NGVs. Information also was obtained on key parameters that determine the economic viability of shredder operations in the United States. It is useful to note that the future economic viability of the recycle industry will be a function of technical constraints imposed by NGV material changes and by the environmental and social acceptability of any changes that must occur in response to changes in material composition.

Although this study was not funded sufficiently to construct a formal cost model, back-of-theenvelope calculations lead to valuable observations about the potential effects of NGVs on the future economic viability of the industry.

Information was obtained from industry representatives on the following parameters: capital cost, operating cost (e.g., maintenance, labor, energy), the purchase price of scrap cars, the cost of landfill, average shredder capacity, the average price of ferrous metals, and the average prices of non-ferrous metals. A rough calculation of today's industry profitability can be obtained by combining this information with the material composition data in our base-case scenario. Although not reliable as an estimate of the actual profitability of today's shredder operations, this estimate can be used as a base against which the impacts of potential changes in material composition can be evaluated.

According to our industry contacts, shredders alone cost about $\$ 750,000$, while separation equipment ranges from about $\$ 125,000-600,000$. A complete system can cost between $\$ 2-3$ million, although larger systems are in the $\$ 4-5$ million range. If we assume (1) a 4,000 HP unit, with capacity of two cars per minute, costs $\$ 4.5$ million; (2) the unit is operated for 30 hours per week; and (3) the unit has a 15 year life span; the per week capital cost of the facility is about $\$ 6,000$, assuming straight-line depreciation. At the assumed capacity, 3,600 cars will be processed per week. The industry estimates that scrap cars (with their engines already removed-about 600 pounds of ferrous metal) will cost shredder operators about $\$ 100$ each. Thus, the cost of material inputs (i.e., scrap cars) is about $\$ 360,000$ per week. The industry estimates that the typical shredder will experience operating costs of between $\$ 20-\$ 28$ per metric ton. If we assume $\$ 24$ per metric ton, and we assume an average automobile weight of 3,240 pounds (our base case), weekly operating costs will be about $\$ 128,000$. If we assume fluff per vehicle is 760 pounds per car (i.e., the sum of non-metal materials in our base case) or about $24 \%$ of the vehicles weight, the cost of fluff disposal at $\$ 55$ per metric ton is about $\$ 68,000$ per week. Therefore, our total estimated weekly cost under this scenario is about $\$ 562,000$.

On the revenue side, the industry estimates that, on average, shredders get about $\$ 160$ per metric ton for ferrous materials and about five times this price for non-ferrous metals. Our base-case vehicle contains 2,245 pounds of ferrous metals. If we assume the 600 pound engine has been removed before the car is sold to the shredder, the shredder can retrieve about 1,645 pounds of ferrous metals per vehicle. If 3,600 cars are processed each week, revenues from ferrous materials sales will be 
about $\$ 429 \mathrm{~K}$ per week. Our base-case car also contains about 230 pounds of cast and wrought aluminum. Although not specified in our base case, the average U.S. vehicle contained about 45 pounds of copper and 15 pounds of zinc. Thus, total non-ferrous metals total to about 290 pounds per vehicle. Under our assumptions, the value of non-ferrous metals to the shredder is about $\$ 378 \mathrm{~K}$ per week. (Note that some of the copper and zinc components may be removed by hand dismantling prior to shredding or prior to purchase by the shredder operators. The value of these non-ferrous metals, therefore, should be considered as an upper bound.)

Given the assumptions of our simplified analysis, our hypothetical shredder operator has weekly costs of about $\$ 562 \mathrm{~K}$ and weekly revenues of about $\$ 807 \mathrm{~K}$, or net profits of about $\$ 245 \mathrm{~K}$. Once again, this should be considered as a crude estimate. Obvious costs, such as taxes and the cost of land, have not been included. These crude numbers, nonetheless, can be used as a base against which the impacts of our NGV scenarios can be evaluated.

A conclusion common to all of our material scenarios is the low cost of capital. In our hypothetical example, capital costs contribute only 1 percent of total cost. Operating costs (23\% of the total), scrap vehicle costs (64\% of the total), and the cost of fluff disposal (12\%) are dominant. From another perspective, the total undepreciated capital value of shredders in the United States is only about $\$ 950$ million (211 units at about $\$ 4.5$ million each). While large in absolute terms, this capital investment is relatively small number compared to other life-cycle stages.

\subsection{Ultra-Light Steel}

Our ultra-light-steel scenario poses few, if any, issues for recycling. Shredder and post-shredder technology would not need to be changed. No significant technical concerns were identified.

From an economic perspective, revenues would be reduced. Given our assumptions, ferrous content is reduced by 298 pounds per vehicle, while quantities of other materials remain unchanged.

Assuming all other costs remain unchanged from our base case, our hypothetical shredder operator would experience revenue losses of about $\$ 78 \mathrm{~K}$ per week. This loss could be offset, for example, by a reduction in the price paid for scrap cars from $\$ 100$ to about $\$ 78$ per car.

\subsection{Aluminum}

Our aluminum scenario raises several technical issues worthy of further research. Different forms of aluminum (cast versus wrought, different alloys) are not compatible for all recycling applications. Adhesives used to join different aluminum components and points/coatings may be problematic. As a result, aluminum parts may require hand disassembly prior to shredding (probably at a significantly higher cost). Hand disassembly will require new and aggressive part labeling, at an uncertain cost to the industry. In addition, the value of recycled aluminum from automobiles (currently about $\$ 0.50$ per pound) could decrease if segregation of different aluminum types is not feasible. The adoption of one alloy for several or, perhaps, all, applications could significantly reduce obstacles to recycling.

If we assume that the above mentioned problems (which lead to increases in costs and decreases in revenues) do not occur, our aluminum-intensive scenario leads to significant gains in profitability for the recycle industry. All other things being unchanged, our aluminum scenario leads to a revenue increase of $\$ 1,208 \mathrm{~K}$ per week from additional aluminum sales and a revenue loss of $\$ 439 \mathrm{~K}$ from decreased ferrous sales, for a net revenue increase of $\$ 769 \mathrm{~K}$ per week. It is likely that even significant technical obstacles could be overcome by these very large revenue gains. 


\subsection{Magnesium}

The recycle industry raised significant concerns about the increased use of magnesium. According to industry representatives, the increased use of magnesium would increase the risk of fires, thereby requiring additional equipment and possibly new technologies. Magnesium also could raise significant safety issues and could drive up liability costs. New separation technologies may also be required to separate the magnesium from the aluminum. Additional work is needed to more fully address these concerns from technical and economic perspectives.

If the magnesium can be separated and collected for recycling, a more magnesium-intensive vehicle would be more profitable to shredder operators, all else being unchanged. When compared to our base-case-scenario, our magnesium scenario would result in reduced weekly revenues from lower ferrous sales of about $\$ 147 \mathrm{~K}$ and increased revenues of about $\$ 230 \mathrm{~K}$ from the sale of magnesium.

\subsection{Composites}

In general, the addition of composites (either glass-reinforced composites or carbon-reinforced composites) will not affect the operation of the shredder or affect the operation of down-stream technologies. Composites, however, do pose a significant economic concern for shredders if those composites must be landfilled. Composites also pose public-acceptance issues, in that the public is generally opposed to landfilling. Few environmental concerns are associated with composites, other than the general objection to landfilling.

Work is currently being done to identify potential uses for scrap composites. However, current applications are very limited and the cost of separation and processing is high. Composites could be used as a fuel, but they face cost and potential environmental barriers. Composites can also be used as fillers with virgin resin. However, it is likely that the cross-linked molecular bonds of automotive composites will prevent their use in new automotive parts.

Assuming all else unchanged, composites will impact the economic viability of shredders negatively. Under our assumptions, revenues from the sale of ferrous metals will decrease by about $\$ 247 \mathrm{~K}$ per week and the cost of fluff disposal will increase by about $\$ 59 \mathrm{~K}$ per week. This increase in cost and decrease in revenues could be balanced by a decrease in the price paid for scrap cars from $\$ 100$ to $\$ 15$ per car. However, it is unlikely that scrap cars can be provided to shredders at a price of $\$ 15$ per car. The financial viability of shredders, of course, is made worse by anticipated increases in the cost of landfilling. Without technological developments to increase revenues and/or decrease cost, or the provision of some type of subsidy to the recycle industry, the economic viability of our current automobile recycle infrastructure would be in question. 


\section{CONCLUSIONS}

Our analysis has identified potential issues and difficulties that could arise at each life cycle stage from the substitution of light weight materials for steel. Although cross-material comparisons are inappropriate because our scenarios assume maximal use of each respective substitute material, it is revealing to examine which materials pose challenges at certain life-cycle stages. This information is depicted in Figure 8-1. These issues represent changes that are potentially important for the nation's economy and those which may require attention by the PNGV program if they are to occur as needed.

Raw materials to produce each of the replacement materials are sufficiently available and adequate mining or extraction capacity exists for each. However, challenges are possible at the material production stage for three of the four materials. For aluminum and magnesium the difficulties are associated with requirements for significant new production capacity, necessary for aluminum because new production equipment will be needed to produce the material in a cost-effective manner and for magnesium because current production capacity is inadequate. The required capacity investment for magnesium to meet demand in 2030 is $\$ 13.1$ billion. Both materials also would sharply increase energy requirements, and both industries would likely develop mostly-if not entirely-outside the United States. To produce the carbon-based fiber to meet PNGV demand in 2015 , an entire new industry must be developed-a $\$ 4.6$ billion investment. Significant environmental concerns also are associated with carbon fiber production. The glass fiber industry is far more established, but operates at capacity. An estimated investment of $\$ 350$ million would be required to meet demand in 2015 . However, if applications require higher-grade glass fibers, the required investment would increase more than 5-fold. Significant growth would also be required in the composites industry for either carbon- or glass-based fibers.

Only composites present a serious challenge at the component fabrication life-cycle stage. The advanced polymer composites likely to be required for NGVs currently account for less than $1 \%$ of the total polymer composite market and represent only 4-5\% of NGV demand in 2015 . For each of the other materials, fabrication technologies are well developed but some additional production capacity would be required. Although fabrication methods exists for each material type, the products they produce are not subject to the same performance (strength) and cost requirements that would be required in automotive applications. It could take several product generations to develop this knowhow in an automotive setting. The lack of know-how and the need to develop and refine new production methods are not necessarily barriers to materials substitution, but they are barriers to rapid large-scale materials substitution.

Another general issue arises related to component fabrication. Because automobiles are designed as systems of components, substitution of one material for another in a component is easiest when the component is weakly integrated into the vehicle design. For example, substituting aluminum for steel in a wheel reduces the weight of the wheel but may have little or no effect on the wheel's size or performance. Such a change might allow a change in the design of the vehicle frame or other components, but it probably would not require it. On the other hand, substituting aluminum for steel in the frame could change component dimensions and require changes in other components to accommodate this. The industry is thus likely to prefer to substitute materials in components that do not require extensive changes in vehicle design, because only the equipment for that component needs to be retooled. Moreover, this type of change is relatively easy to reverse if the costs of different materials or production processes change. Moving from present unibody construction to spaceframe construction necessarily entails changes in large numbers of components. However, this type of change may be necessary to reach the substitution targets in the NGV scenarios. Automakers may need incentives to undertake a rapid, major design change for a major part of their product. lines. 


\begin{tabular}{|c|c|c|c|c|c|c|}
\hline & \multicolumn{6}{|c|}{ Life-cycle stage } \\
\hline Material & $\begin{array}{l}\text { Ore } \\
\text { mining/ } \\
\text { extraction }\end{array}$ & $\begin{array}{l}\text { Material } \\
\text { production }\end{array}$ & $\begin{array}{l}\text { Component } \\
\text { fabrication }\end{array}$ & $\begin{array}{l}\text { Vehicle } \\
\text { assembly }\end{array}$ & $\begin{array}{l}\text { Use and } \\
\text { repair }\end{array}$ & Recycling \\
\hline ULSAB & & & & & & \\
\hline Aluminum & & & & & & \\
\hline Magnesium & & & & & & \\
\hline Composite & & & & & & \\
\hline
\end{tabular}

Figure 8-1. Life-cycle stages in which challenges are expected. 
Vehicle assembly presents challenges for ULSAB, aluminum and composites. For ULSAB, a radical change in design will require new assembly methods; however, vehicle assembly is expected to be much faster than for baseline vehicles. Likewise, aluminum and composites would require new joining methods and, thus, new infrastructures to carry them out.

At the use-and-repair life cycle stage, aluminum and composites-materials that allow parts consolidation-present challenges. The consolidated parts could make damage repair more expensive by requiring replacement of larger components after an accident, and this could increase the cost of automobile insurance and thus the cost of owning and operating the vehicle.

The three, non-steel replacement materials present potential recycling difficulties. Composite would not affect the shredder operation but would reduce the amount of ferrous material for recycling and increase the amount of material for landfill, thus threatening the economic viability of the current recycling infrastructure. Aluminum and magnesium, on the other hand, present operational difficulties. Magnesium would increase the risk of fires potentially decreasing worker safety, and increasing liability costs thereby requiring new technologies. With aluminum, several technical problems arise, e.g., the incompatibility of different alloys, contamination from paints and adhesives, and potential requirements for hand disassembly. If these problems can be overcome, intensive use of aluminum could favorably affect the financial viability of the industry. 



\section{REFERENCES}

American Ceramic Society Bulletin (ACSB) 1996. "Minerals Review: Silica," 75(6, June):151-152.

American Metal Market (AMM) 1995. Metal Statistics 1995, New York, NY.

Bird, Anthony 1993. "Changing patterns in aluminum production costs: History and prospects," Natural Resources Forum 17(2, May):151-155.

Blau, J. R. 1996. "Porsche Prepares for Next Step in Ultralight Steel Body Effort," Machine Design, pp. 42-48, February 22.

Busch, J.V., F.R. Field and J.P. Clark 1987. "Economics of Automobile Panels," Paper presented at ATA-CNR Seminar -- Innovation in Materials for the Transportation Industry, Torino, November 4-6.

Curlee, T. R., S. Das, C. G. Rizy, and S. M. Schexnayder 1994. Recent Trends in Automobile Recycling: An Energy and Economic Assessment, ORNL/TM-12628, Oak Ridge National Laboratory, Oak Ridge, TN.

Davis, Stacy C. 1995. Transportation Energy Data Book: Edition 15, ORNL-6856, Oak Ridge National Laboratory, Oak Ridge, TN, June.

Delong, D.J. 1994. "Carbon Fiber Economics/Applications," Paper presented at the Gorham/Intertech Conference, July 21.

Dieffenbach, J.R. And A.E. Mascarin 1993. "Body-in-White Materials Systems: A LifeCycle Cost Comparison," Journal of Materials 45(6, June):16-19.

Eckert, C.H. 1995. Personal communication, Kline \& Company, Inc., Fairfield, NJ, August 1.

EIA (Energy Information Administration) 1996. Annual Energy Outlook 1996: With Projections to 2015, DOE/EIA-0383(96), Office of Integrated Analysis and Forecasting, U.S. Department of Energy, Washington, DC, January.

Elvers, Barbara, James F. Rounsaville, and Gail Schultz 1990. Ullmann's Encyclopedia of Industrial Chemistry. New York: VCH Publishers.

EPA (U.S. Environmental Protection Agency) 1995. Compilation of Air Pollutant Emission Factors, Vol. I: Stationary Point and Area Sources, AP-42, Research Triangle Park, NC.

Farrissey, W.J. 1991. "Recycle of Thermoset Polyurethanes," RecyclingPlas VI Conference: Plastics Recycling as Future Business Community," Technomic Publishing Company, Inc., Lancaster, PA, p.15.

Gaines. L. and Shen 1980. "Energy and Material Flows in the Production of Olefins and Their Derivatives," ANL/CNSV-9, Argonne National Laboratory, Argonne, $\mathbb{L}$, August.

Gaines, L., 1996 Personal communication. Argonne National Laboratory, Argonne, Illinois, August 19. 
Grande, J.A. 1995. "U.S. Composites Shipments Are Projected to Rise 4.3\% in '95." Modern Plastics, (October):36-7.

Johnsen, M.R. 1995. "Steel Consortium Reveals a Lighter Auto Body Design," Welding Journal, p. 19, November.

Leach, R.E. 1995. Personal communication. Center for Composites Manufacturing Technology, Oak Ridge National Laboratory, Oak Ridge, TN, August 7.

Lee, S.M., T. Jonas, and G. DiSalvo. 1991. "The Beneficial Energy and Environmental Impact of Composite Materials -- An Unexpected Bonus," SAMPE Journal, 27(2):19-25, March/April.

Lee, S.M., T. Jones, and G. DiSalvo 1991. "The beneficial energy and environmental impact of composite materials-An expected bonus," SAMPE Joumal 27(2), Mar-April:19-25.

McDermott, J. 1996. "Developing the Demographics of the Composites Industry," Composites Fabrication, (April):12-17.

Miesel, G. 1995. Personal communication, Ashland Chemical, Michigan, August 2.

Minerals Yearbook 1994. Washington, US Geological Survey, 1996.

Modern Metals 1994. "Aluminum in cars: $191 \mathrm{lbs}$ and rising". February, pp. 20-24.

Modern Plastics 1995. "A Year of Robust Growth, Rising Costs," pp. 63-68, January.

Owens Corning Fiberglas Corporation (OFC) 1996a. Owens Corning: 1996 Fact Book. Toledo, Ohio, January.

Owens Corning Fiberglas Corporation (OFC) 1996b. Owens Corning Composites Capacity Increase Backgrounder. Toledo, Ohio, January.

Pierce, B.L., H. Coward, and F.T. Sparrow 1984. Industrial Process Models of Electricity Demand (Volume 4: The Aluminum Industry). Report EPRI-EA-3507/vol 4. Palo Alto, CA: Electric Power Research Institute.

PNGV (Partnership for a New Generation of Vehicles) 1995. "Report of Workshop on Aluminum Vehicle Structures." Detroit, MI, Oct. 17.

Prescott, R. 1996. Personal communication, Akzo Nobel, Fortafil Fibers, Inc., Rockwood, Tennessee, June 12.

Prescott, R., 1996. Personal communication, Akzo Nobel, Fortafil Fibers, Inc., Rockwood, Tennessee, August 9.

Read, Brendan B., The New Markets for Stainless Steel," New Steel Vol. 11 66-72: (September 1995).

Resolve, Inc. 1995. "Policy Dialogue Advisory Committee to Develop Options for Reducing Greenhouse Gas Emissions from Personal Motor Vehicles," draft final report, Washington, D.C., August. 
Samways, Norman L. 1995 Developments in the North American Iron and Steel Industry 1994," Iron and Steel Engineer Vol. 72 No. 2, D1-D24: February.

Samways, Norman L. 1996 Developments in the North American Iron and Steel Industry 1995," Iron and Steel Engineer Vol. 73 No. 2, D1-D24: February.

Sawinski, Diane M., ed. 1995 U.S. Industry Profiles: The Leading 100, Gale Research Inc., Michigan.

Sullivan, J. L. and J. Hu 1995. "Life Cycle Energy Analysis for Automobiles," SAE Paper No. 951829, Fall.

U. S. Department of Commerce 1990. BEA Regional Projections to 2040: Volume 1 -States, U.S. Department of Labor, June.

U.S. Department of Commerce 1990. "Current Industrial Reports: Survey of Plant Capacity," Report No. MQ-C1(92)-1, Bureau of the Census, Washington, DC, March.

United States Geological Survey (USGS) 1996a. "Iron and Steel: Mineral Commodity Summaries," Reston, VA, January.

United States Geological Survey (USGS) 1996b. "Iron and Steel: Minerals Yearbook 1994," Reston, VA.

United States Geological Survey (USGS) 1996c. "Iron Ore: Mineral Commodity Summaries," Reston, VA, January.

United States Geological Survey (USGS) 1996d. "Iron Ore: Minerals Yearbook 1994," Reston, VA.

Wilhelm, Paul J. 1995 "Managing Change in the Steel Industry," Iron and Steel Engineer 2(78, August):55-57.

Wuagneux, E.L. 1995. "Glass: A Market On The Cutting Edge," Nonwovens Industry, pp. 29-34, August. 



\section{Internal Distribution}

1. S. M. Cohn

2. G. E. Courville

3-12. T. R. Curlee

13. S. Das

14. S. C. Davis

15. S. W. Hadley

16. H. W. Hayden

17. S. G. Hildebrand

18. P. N. Leiby

19. S. P. Miaou

20. C. I. Moser

21-25. S. M. Schexnayder

26. R. B. Shelton

27. P. S. Sklad

28. D. M. Vogt

29. R. E. Ziegler

30. ORNL Patent Office

31. Central Research Library

32. Document Reference Section

33-34. Laboratory Records

35. Laboratory Records - RC

\section{External Distribution}

36. Dr. Lilia A. Abron, President, PEER Consultants, P.C., 1460 Gulf Blvd., 11 th Floor, Clearwater, Florida 34630

37. E. G. Cumesty, ORNL Site Manager, Department of Energy, Oak Ridge National Laboratory, Post Office Box 2008, Oak Ridge, Tennessee 37831-6269

38. Dr. Thomas E. Drabek, Professor, Department of Sociology, University of Denver, Denver, Colorado 80208-0209

39. Mr. Kevin Green, DTS-24, Volpe National Transportation Systems Center, 55 Broadway, Kendall Square, Cambridge, Massachusetts 02142

40. Dr. Don Hillebrand, SAE Fellow, Office of Science and Technology Policy, OEOB 427, Washington, D.C. 20502

41. Dr. Larry R. Johnson, Director, Center for Transportation Research, Argonne National Laboratory, ES/362-B201, 9700 Cass Avenue, Argonne, Illinois $60439-4815$

42. Mr. John D. Maples, 2331 Putnam Lane, Crofton, Maryland 21114

43. Office of Scientific and Technical Information, Post Office Box 62, Oak Ridge, Tennessee 37831 


\section{External Distribution (Cont'd)}

44. Mr. P. Richard Rittelmann, FAIA, Executive Vice President, Burt Hill Kosar Rittelmann Associates, 400 Morgan Center, Butler, Pennsylvania, 16001-5977

45. Mr. Scott Staley, U.S. Dept. of Commerce, Technology Administration, Room. 4845, 14th Street \& Constitution Avenue, NW, Washington, D.C. 20230

46. Dr. Susan F. Tierney, The Economic Resource Group, Inc. One Mifflin Place, Cambridge, Massachusetts 02138

47. Dr. C. Michael Walton, Ernest H. Cockrell Centennial Chair, in Engineering and Chairman, Department of Civil Engineering, University of Texas at Austin, Austin, Texas $78712-1076$

48. Dr. Michael Q. Wang, Center for Transportation Research, Argonne National Laboratory, ES/362-B215, 9700 Cass Avenue, Argonne, Illinois 60439-4815 